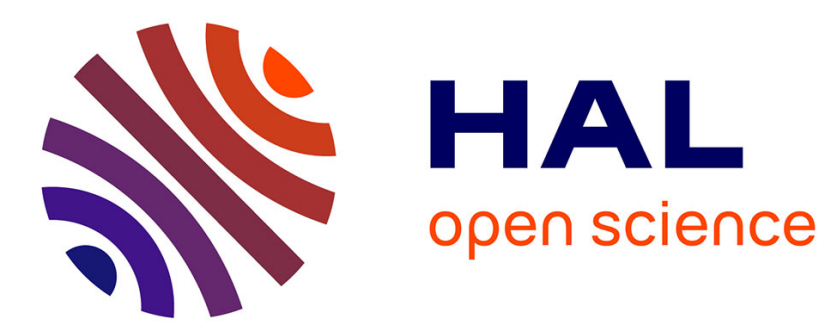

\title{
On the Role of Progressive Taxation in a Ramsey Model with Heterogeneous Households
}

Stefano Bosi, Thomas Seegmuller

\section{To cite this version:}

Stefano Bosi, Thomas Seegmuller. On the Role of Progressive Taxation in a Ramsey Model with Heterogeneous Households. 2008. halshs-00331299

\section{HAL Id: halshs-00331299 \\ https://shs.hal.science/halshs-00331299}

Submitted on 16 Oct 2008

HAL is a multi-disciplinary open access archive for the deposit and dissemination of scientific research documents, whether they are published or not. The documents may come from teaching and research institutions in France or abroad, or from public or private research centers.
L'archive ouverte pluridisciplinaire HAL, est destinée au dépôt et à la diffusion de documents scientifiques de niveau recherche, publiés ou non, émanant des établissements d'enseignement et de recherche français ou étrangers, des laboratoires publics ou privés. 


\section{Documents de Travail du Centre d'Economie de la Sorbonne}
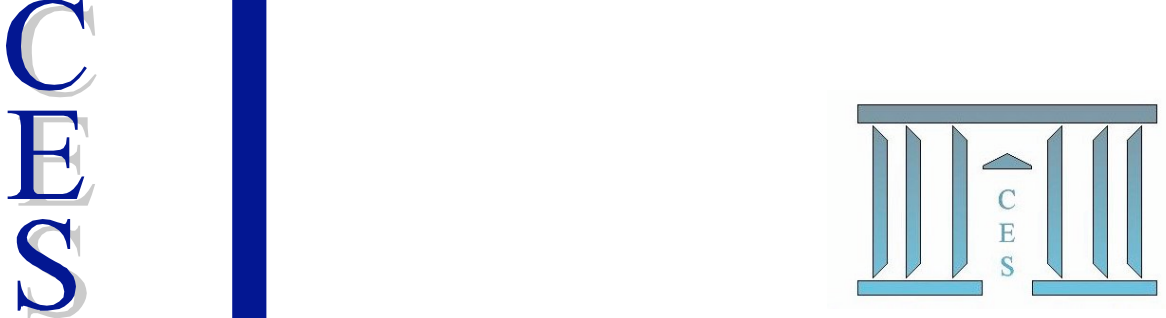

On the Role of Progressive Taxation in a Ramsey Model with Heterogeneous Households

Stefano Bosi, Thomas SEEGMULLER

2008.51

CENTRE NATIONAL

DE LARECHERCHE

SCIENTIFIQUE 


\title{
On the Role of Progressive Taxation in a Ramsey Model with Heterogeneous Households*
}

\author{
Stefano BOSI ${ }^{\dagger}$ and Thomas SEEGMULLER ${ }^{\ddagger}$
}

June 23, 2008

\footnotetext{
*This work was supported by French National Research Agency Grant (ANR-05-BLAN0347-01). We would like to thank Carine Nourry and participants of the workshop "Growth with Heterogeneous Agents: Causes and Effects of Inequality" held in Marseille on June 16-17, 2008, for helpful comments. All remaining errors or omissions are our own.

${ }^{\dagger}$ Corresponding author. EQUIPPE (Université de Lille 1) and EPEE (Université d'Evry). Département d'Economie, Université de Lille 1. Bât. SH2, Cité Scientifique. 59655, Villeneuve d'Ascq Cedex, France. Tel: + 33 (0)3 203370 12. E-mail: stefano.bosi@orange.fr.

${ }^{\ddagger}$ Paris School of Economics and CNRS, Centre d’Economie de la Sorbonne. 106-112, bd. de l'Hôpital. 75647, Paris Cedex 13. France. Tel: + 33 (0)1 440781 99. Fax: + 33 (0)1 44 0782 31. E-mail: seegmu@univ-paris1.fr.
} 


\begin{abstract}
The aim of this paper is to study the role of progressive tax rules on the allocations of steady state and the stability properties in a Ramsey economy with heterogeneous households and borrowing constraints. Since labor supply is elastic, considering different tax rates on capital and labor incomes is relevant. The steady state analysis allows us to highlight the existence of different types of stationary equilibria. While patient agents always hold capital, impatient ones have or not positive savings, depending on the level of real interest rate. Furthermore, it is not always optimal for all households to have a positive labor supply.

Studying the comparative statics and local dynamics, we focus on the steady state with a segmented population: patient households own the whole stock of capital, while the impatient ones are workers. Varying the population sizes and the tax rates, we underline the crucial role of fiscal progressivity and endogenous labor. Moreover, in contrast to many contributions, we prove that progressive tax rules can promote expectation-driven fluctuations and endogenous cycles, which means that progressivity can be inopportune to stabilize macroeconomic volatility.
\end{abstract}

Keywords: Progressive taxation, heterogeneous agents, borrowing constraint, endogenous labor supply, steady state allocation, macroeconomic stability.

\title{
Résumé
}

L'objectif de ce papier est d'étudier le rôle de taxes progressives sur les allocations stationnaires et les propriétés de stabilité dans un modèle de Ramsey avec agents hétérogènes et contraintes d'emprunt. Comme l'offre de travail est élastique, il est pertinent de considérer des taux de taxe différents sur les revenus du capital et du travail. L'analyse de l'état stationnaire nous permet d'exhiber différents types d'équilibres. Alors que les agents patients détiennent toujours du capital, les impatients vont avoir une épargne positive ou non suivant le niveau du taux d'intérêt. Par ailleurs, il n'est pas toujours optimal pour tous les agents d'offrir du travail.

Pour étudier la statique comparative et la dynamique locale, nous concentrons notre attention sur un état stationnaire caractérisé par une population segmentée : les agents patients détiennent tout le stock de capital et les impatients sont les seuls à offrir du travail. Faisant varier les tailles des populations ou le niveau des taux de taxes, nous soulignons le rôle prépondérant de la progressivité marginale et du travail endogène. De plus, au contraire de la plupart des résultats existants, nous montrons que l'introduction de taxes progressives peut favoriser l'émergence de fluctuations endogènes, signifiant que la progressivité peut être inadéquate pour stabiliser la volatilité macroéconomique.

Mots-clés: Taxation progressive, agents hétérogènes, contrainte d'emprunt, offre de travail endogène, état stationnaire, stabilité macroéconomique.

JEL classification: C62, H20, E32. 


\section{Introduction}

Since the seminal contribution of Schmitt-Grohé and Uribe (1997), several papers have analyzed the (de-)stabilizing role of balanced-budget fiscal policy rules. As shown by Guo and Lansing (1998), it is well-known that in one-sector Ramsey model with representative agents, progressive tax rates can stabilize macroeconomic fluctuations, by preventing the economy from expectations-driven fluctuations. Introducing variable tax rates in the Benhabib and Farmer (1994) model, they recognize in the labor market and the progressivity on labor income the key ingredients for macroeconomic (in-)stability.

However, there is little doubt that the analysis of taxation (through its possible redistributive effects) and progressivity (under the assumption that each individual is aware of the tax rule and the effects on his disposable income) makes more sense in models with heterogeneous households. This is why in this paper, the dynamic effects of progressivity in taxation are studied taking into account agents' heterogeneity.

When infinite-lived households, who face a borrowing constraint, have not only heterogeneous endowments and instantaneous utility functions, but also heterogeneous discount factors, Sarte (1997) shows that, under a progressive taxation on income, even the less patient consumers can hold capital at the steady state. Therefore, in contrast to the case without government intervention (see Becker (1980)), the steady state allocation is no longer characterized by a degenerate capital distribution, where the most patient agent hold the whole capital stock. ${ }^{1}$ The reason is that the after-tax interest rates can be different for each type of household because of the progressive taxation. In a quite similar model, Sorger (2002) has also studied local dynamics in a neighborhood of the steady state where all consumers hold capital. He gives an example where the steady state can be locally indeterminate and endogenous cycles of period two can occur.

Our paper aims to make a more general and extensive analysis of progressive tax rules on the allocations of steady state and local dynamics in economies with heterogeneous households. In the spirit of Bosi and Seegmuller (2007), we extend the Ramsey model with borrowing constraints and heterogeneous households, i.e. with heterogeneous capital endowments, instantaneous utility functions and discount factors, to the case with endogenous labor supply. In contrast to Sarte (1997) and Sorger (2002), such a framework allows us to take in account differentiated taxes on capital and labor incomes. ${ }^{2}$ Without loss of generality, we consider two types of heterogeneous households and we provide a complete analysis of stationary solutions. In addition, focusing on the steady state where only the most patient owns capital, we characterize exhaustively

\footnotetext{
${ }^{1}$ Recent contributions also prove the existence of steady states where impatient consumers, with market power in the capital market, can hold capital. See, for instance, Becker and Foias (2007), Sorger (2002, 2004, 2008).

${ }^{2}$ Hence, we also throw a bridge between the two aforementioned approaches: the former with representative agents and endogenous labor supply; the latter with heterogeneous consumers without preferences on leisure.
} 
the local dynamics. Namely, we show that a higher marginal progressivity ${ }^{3}$ in capital or labor taxation not necessarily stabilizes business cycles, but can rather promote expectations-driven fluctuations and endogenous cycles. ${ }^{4}$

After characterizing the intertemporal equilibrium, we show that, when the stationary value of the real interest rate is not too large, there exists a steady state where only the most patient households supply capital. In contrast, when it is large enough, there exists a stationary equilibrium where all the agents hold capital. We also prove that it is not always optimal for anybody to supply labor. Concerning the uniqueness of the stationary equilibrium, we highlight the crucial role of marginal progressivity in capital taxation.

We pursue the steady state analysis by considering the effects of a variation in the population sizes of patient and impatient households as well as in the tax rates, on the one hand, on the stationary values of aggregate capital and product and, on the other hand, on individual incomes and welfare. For the sake of simplicity, we focus on a steady state where only patient consumers hold capital and only impatient supply labor. ${ }^{5}$ Such an equilibrium is of interest because of the endogenous split of population in two classes, capitalists and workers (see also Bosi and Seegmuller (2007)), and provides a foundation of models with social segmentation such as Mankiw (2000), Michel and Pestieau (1999) or Woodford (1989). ${ }^{6}$ Among others, we show that the ratio of sizes patient/impatient agents affects the capital-labor ratio because of the progressivity in capital taxation. Moreover, taking into account an elastic labor supply can reverse some results, according to the degree of marginal progressivity and the elasticities of intertemporal and capital-labor substitution.

In this paper, dynamics are studied through a local analysis, focusing on the neighborhood of the steady state which is characterized, as seen above, by a polar segmentation in patient capitalists who hold capital, and impatient workers who supply labor. We show that marginal progressivity promotes the existence of cycles by increasing the degree of capital-labor substitution compatible with the existence of two-period cycles. A higher marginal progressivity in capital or labor taxation promotes also expectation-driven fluctuations by enlarging the range of parameter values (capital-labor substitution) compatible with indeterminacy.

To further analyze the role of marginal progressivity of labor taxation, we

\footnotetext{
${ }^{3}$ Throughout this paper, the progressivity of taxation is defined in marginal terms. We observe that such a measure is one adopted by Musgrave and Thin (1948) in their seminal paper.

${ }^{4}$ Notice that in their recent contributions, Dromel and Pintus (2007) and Lloyd Braga et al. (2008) study the role of progressivity and tax-rate variability on indeterminacy within a model à la Woodford (1986) where consumers are also heterogeneous. But, in contrast to our paper, they assume an ex-ante segmentation of the population in two types of households and introduce money. Moreover, none of these papers consider a simultaneous taxation on both capital and labor income.

${ }^{5}$ Such a stationary equilibrium where a part of population is finance constrained and consumes his current income is in accordance with empirical evidence. See for instance Bacchetta and Gerlach (1997) or Cushing (1992). For a critical survey, see Attanasio (1999).

${ }^{6}$ Thibault (2005) obtains a closely related result using an overlapping generations model with heterogeneous altruistic agents.
} 
consider the occurrence of business cycles when patient agents supply labor, while holding the capital stock. For the sake of simplicity, a flat tax on capital income is introduced. As above, we find that increasing marginal progressivity promotes the occurrence of endogenous cycles. In addition, local indeterminacy arises under a sufficiently large (distortionary) tax rate on capital income. Then, a larger progressivity on labor tax increases the range of capital-labor substitution compatible with expectations-driven fluctuations, but not for whatever parametrization.

Therefore, in contrast to Ramsey models with heterogeneous households but without taxation, ${ }^{7}$ the steady state, where only the most patient households have positive savings, can be locally indeterminate. As seen above, capital taxation is a key ingredient for the emergence of fluctuations due to self-fulfilling expectations. Moreover, in most of the cases, the larger the marginal progressivity, the more likely expectation-driven fluctuations and endogenous cycles. Thus, our conclusions differ from most of those existing in the theoretical literature concerned with one-sector models. However, it is not unworthy to notice that a peculiarity of our model is a kind of market incompleteness because of the existence of a borrowing constraint. More generally, this paper allows us to argue that, following for instance redistributive arguments, one should increase carefully progressivity or the tax rate on capital because this can promote macroeconomic volatility.

This paper is organized as follows. In the next section, we present the model. In Section 3, we characterize the intertemporal equilibrium. Section 4 is devoted to the existence and uniqueness of steady state. In Section 5, we study the comparative statics of a steady where patient consumers supply capital and impatient ones work. In Section 6, we analyze the local dynamics, while concluding remarks are provided in Section 7. Many technical details and proofs are gathered in the Appendix.

\section{The model}

We consider a discrete time $(t=0,1, \ldots, \infty)$ model with three types of agents: heterogeneous consumers, a representative firm and the government.

\subsection{Consumers}

Households are represented by infinite-lived heterogeneous agents with endogenous labor supply and borrowing constraints. Consumers have different initial capital endowments and preferences. In this respect, there is a twofold kind of heterogeneity in tastes: on the one hand, heterogeneous discounting; on the other hand, different instantaneous utilities in consumption and leisure across the households.

\footnotetext{
${ }^{7}$ See for instance Becker and Foias $(1987,1994)$, where labor supply is exogenous, and Bosi and Seegmuller (2007), where labor supply is elastic.
} 
Without loss of generality, assume that there are two types of heterogeneous infinite-lived agents, labeled by $i=1,2$ according to their discount factors:

$$
0<\beta_{2}<\beta_{1}<1
$$

Total population is constant, with size $n>0$. The population sizes of both types of consumers are also constant. To fix ideas, $n_{i}$ denotes the population size of households having the discount factor $\beta_{i}$, with $n_{1}+n_{2}=n$.

A consumer $i$ is endowed with the initial amount of capital $k_{i 0} \geq 0$, such that the initial aggregate capital stock is strictly positive, $K_{0}=\sum_{i=1}^{2} n_{i} k_{i 0}>0,{ }^{8}$ and, at each period, with one unit of time that he shares between labor and leisure. We denote his consumption and labor supply at period $t$ with $c_{i t}$ and $l_{i t}$. Preferences are represented by a separable utility function:

$$
\sum_{t=0}^{\infty} \beta_{i}^{t}\left[u_{i}\left(c_{i t}\right)+v_{i}\left(1-l_{i t}\right)\right]
$$

satisfying the following assumption:

Assumption $1 u_{i}\left(c_{i}\right)$ and $v_{i}\left(1-l_{i}\right)$ are continuous functions defined on $[0,+\infty)$ and $[0,1]$, and $C^{2}$ on $(0,+\infty)$ and $(0,1)$, respectively; strictly increasing $\left(u_{i}^{\prime}\left(c_{i}\right)>\right.$ $\left.0, v_{i}^{\prime}\left(1-l_{i}\right)>0\right)$ and strictly concave $\left(u_{i}^{\prime \prime}\left(c_{i}\right)<0, v_{i}^{\prime \prime}\left(1-l_{i}\right)<0\right)$. In addition, the Inada conditions $\lim _{c_{i} \rightarrow 0} u_{i}^{\prime}\left(c_{i}\right)=\lim _{l_{i} \rightarrow 1} v_{i}^{\prime}\left(1-l_{i}\right)=+\infty$ are verified.

The intertemporal substitution is captured by the following elasticities:

$$
\left(\sigma_{1 i}, \sigma_{2 i}\right) \equiv\left(-\frac{u_{i}^{\prime}\left(c_{i}\right)}{c_{i} u_{i}^{\prime \prime}\left(c_{i}\right)},-\frac{v_{i}^{\prime}\left(1-l_{i}\right)}{\left(1-l_{i}\right) v_{i}^{\prime \prime}\left(1-l_{i}\right)}\right)
$$

Note that Assumption 1 implies $\sigma_{1 i}, \sigma_{2 i}>0$. Throughout this paper, the final good is chosen as the numeraire; $r$ and $w$ denote the real interest rate and the real wage, respectively, while $\delta \in(0,1)$ the capital depreciation rate.

Each consumer maximizes (2) with respect to $\left(k_{i t+1}, c_{i t}, l_{i t}\right)_{t=0}^{\infty}$ under sequences of borrowing constraints $k_{i t+1} \geq 0$, positive labor supply $l_{i t} \geq 0$, and budget constraints:

$$
c_{i t}+k_{i t+1}-(1-\delta) k_{i t}=g_{k}\left(r_{t} k_{i t}\right)+g_{l}\left(w_{t} l_{i t}\right)
$$

In equation (4), $g_{k}\left(r_{t} k_{i t}\right)$ and $g_{l}\left(w_{t} l_{i t}\right)$ respectively represent the after-tax capital and labor income. We assume that these two functions have the following properties: ${ }^{9}$

Assumption 2 The function $g_{k}\left(y_{k}\right):[0,+\infty) \rightarrow[0,+\infty)\left(g_{l}\left(y_{l}\right):[0,+\infty) \rightarrow\right.$ $[0,+\infty))$ is continuous, with $g_{k}(0)=0\left(g_{l}(0)=0\right)$, and $C^{2}$ on $(0,+\infty)$. Moreover, it satisfies $0<g_{k}^{\prime}\left(y_{k}\right) \leq 1\left(0<g_{l}^{\prime}\left(y_{l}\right) \leq 1\right), g_{k}^{\prime \prime}\left(y_{k}\right) \leq 0 \quad\left(g_{l}^{\prime \prime}\left(y_{l}\right) \leq 0\right)$ for all $y_{k}>0\left(y_{l}>0\right), \lim _{y_{k} \rightarrow 0} g_{k}^{\prime}\left(y_{k}\right)>\varepsilon_{k}>0$ and $\lim _{y_{l} \rightarrow 0} g_{l}^{\prime}\left(y_{l}\right)>\varepsilon_{l}>0$, where both $\varepsilon_{k}$ and $\varepsilon_{l}$ are constant.

\footnotetext{
${ }^{8}$ This means that at least one type of households has a strictly positive endowment of capital stock.

${ }^{9}$ To simplify the exposition, we use the notations $y_{k} \equiv r k_{i}$ and $y_{l} \equiv w l_{i}$.
} 
Note that the after-tax capital (labor) income $g_{k}\left(y_{k}\right)\left(g_{l}\left(y_{l}\right)\right)$ is increasing, concave, and satisfies $g_{k}\left(y_{k}\right) \leq y_{k}\left(g_{l}\left(y_{l}\right) \leq y_{l}\right)$. Therefore, the tax function $\tau_{k}\left(y_{k}\right) \equiv y_{k}-g_{k}\left(y_{k}\right) \geq 0\left(\tau_{l}\left(y_{l}\right) \equiv y_{l}-g_{l}\left(y_{l}\right) \geq 0\right)$ is non-decreasing and convex. Moreover, $\tau_{k}\left(y_{k}\right) / y_{k}=1-g_{k}\left(y_{k}\right) / y_{k}$ and $\tau_{l}\left(y_{l}\right) / y_{l}=1-g_{l}\left(y_{l}\right) / y_{l}$ are increasing. This ensures that both taxes satisfy usual properties of marginal and average progressivity. Notice that the fiscal policy we consider generalizes Sarte (1997) and Sorger (2002) to the case where the tax rules on labor and capital income are different.

The elasticities of after-tax revenues are captured by:

$$
\begin{aligned}
\left(\rho_{1 i}, \rho_{2 i}\right) & \equiv\left(\frac{r k_{i} g_{k}^{\prime}\left(r k_{i}\right)}{g_{k}\left(r k_{i}\right)}, \frac{r k_{i} g_{k}^{\prime \prime}\left(r k_{i}\right)}{g_{k}^{\prime}\left(r k_{i}\right)}\right) \\
\left(\omega_{1 i}, \omega_{2 i}\right) & \equiv\left(\frac{w l_{i} g_{l}^{\prime}\left(w l_{i}\right)}{g_{l}\left(w l_{i}\right)}, \frac{w l_{i} g_{l}^{\prime \prime}\left(w l_{i}\right)}{g_{l}^{\prime}\left(w l_{i}\right)}\right)
\end{aligned}
$$

In the elasticities of the after-tax capital income and labor income $\rho_{j i}$ and $\omega_{j i}$, the first subscript denotes the order, the second one the type of individual. Assumption 2 implies $\rho_{1 i}, \omega_{1 i} \in(0,1]$ and $\rho_{2 i}, \omega_{2 i} \leq 0$. We further note that the levels of $\left|\rho_{2 i}\right|$ and $\left|\omega_{2 i}\right|$ represent measures of marginal progressivity on capital and labor taxation, respectively.

\section{$2.2 \quad$ Firms}

We denote the aggregate capital and labor with $K_{t}$ and $L_{t}$, and the capitallabor ratio with $k_{t} \equiv K_{t} / L_{t}$. A representative firm produces the final good and maximizes the profit:

$$
Y_{t}-r_{t} K_{t}-w_{t} L_{t}
$$

with respect to the inputs $\left(K_{t}, L_{t}\right)$ under the technology constraint $Y_{t}=F\left(K_{t}, L_{t}\right)$. The production function is characterized as follows: ${ }^{10}$

Assumption $3 F(K, L)$ is a continuous function defined on $[0,+\infty)^{2}$ and $C^{2}$ on $(0,+\infty)^{2}$, homogeneous of degree one, strictly increasing in each argument $\left(F_{K}(K, L)>0, F_{L}(K, L)>0\right)$ and strictly concave $\left(F_{K K}(K, L)<0\right.$, $\left.F_{K K}(K, L) F_{L L}(K, L)>F_{K L}(K, L)^{2}\right)$. In addition, $F(0,0)=0$ and the boundary (Inada) conditions $\lim _{k \rightarrow 0} f^{\prime}(k)=+\infty$ and $\lim _{k \rightarrow+\infty} f^{\prime}(k)<\gamma_{1}$ are satisfied, where $f(k) \equiv F(k, 1)$ denotes the product per labor and $k \equiv K / L$ is the capital intensity.

\footnotetext{
${ }^{10}$ The following notations will hold across the paper: $F_{X_{j}}(X) \equiv \partial F(X) / \partial X_{j}$ and $F_{X_{j} X_{h}}(X) \equiv \partial^{2} F(X) /\left(\partial X_{h} \partial X_{j}\right)$, with $\{j, h\}=\{1,2\}$ and $X \equiv\left(X_{1}, X_{2}\right) \equiv(K, L)$.
} 


\subsection{Government}

Taxes on labor and capital income are used to finance public spending $G_{t}$. Assuming that budget is balanced at each period, we have:

$$
\begin{aligned}
G_{t} & =\sum_{i=1}^{2}\left[\tau_{k}\left(r_{t} k_{i t}\right)+\tau_{l}\left(w_{t} l_{i t}\right)\right] n_{i} \\
& =\sum_{i=1}^{2}\left[r_{t} k_{i t}-g_{k}\left(r_{t} k_{i t}\right)+w_{t} l_{i t}-g_{l}\left(w_{t} l_{i t}\right)\right] n_{i}
\end{aligned}
$$

Note that public expenditures neither affect consumers' preferences nor the production function.

\section{Intertemporal equilibrium}

We start by giving a definition of an equilibrium:

Definition 1 An equilibrium of the economy $E=\left(F, g_{k}, g_{l},\left(k_{i 0}, \beta_{i}, u_{i}, v_{i}, n_{i}\right)_{i=1}^{2}\right)$ is an intertemporal sequence $\left(r_{t}, w_{t}, K_{t}, L_{t}, Y_{t}, G_{t},\left(k_{i t}, l_{i t}, c_{i t}\right)_{i=1}^{2}\right)_{t=0}^{\infty}$ which satisfies the following conditions:

(D1) given the strictly positive sequence $\left(r_{t}, w_{t}\right)_{t=0}^{\infty},\left(K_{t}, L_{t}\right)$ solves the firm's program for $t=0, \ldots, \infty$;

(D2) given $\left(r_{t}, w_{t}\right)_{t=0}^{\infty},\left(k_{i t+1}, c_{i t}, l_{i t}\right)_{t=0}^{\infty}$ solves the consumer's $i$ program for $i=1,2$;

(D3) the public spending $G_{t}$ is determined by the balanced budget rule (7);

(D4) the capital market clears: $K_{t}=\sum_{i=1}^{2} n_{i} k_{i t}$ for $t=0, \ldots, \infty$;

(D5) the labor market clears: $L_{t}=\sum_{i=1}^{2} n_{i} l_{i t}$ for $t=0, \ldots, \infty$;

(D6) the product market clears: $Y_{t}=G_{t}+\sum_{i=1}^{2}\left[c_{i t}+k_{i t+1}-(1-\delta) k_{i t}\right] n_{i}$ for $t=0, \ldots, \infty$.

The next proposition characterizes the intertemporal equilibrium defined above:

Proposition 1 Let an economy E satisfying Assumptions 1-3. Consider the conditions (P1)-(P8) below for $t=0, \ldots, \infty$ and $i=1,2$ :

(P1) $K_{t}>0, L_{t}>0, Y_{t}=F\left(K_{t}, L_{t}\right)>0, k_{i t} \geq 0,0 \leq l_{i t} \leq 1, c_{i t} \geq 0$;

(P2) $r_{t}=F_{k}\left(K_{t}, L_{t}\right)$ and $w_{t}=F_{l}\left(K_{t}, L_{t}\right)$;

(P3) $u_{i}^{\prime}\left(c_{i t}\right) g_{l}^{\prime}\left(w_{t} l_{i t}\right) w_{t} \leq v_{i}^{\prime}\left(1-l_{i t}\right)$, with equality when $l_{i t}>0$; 
(P4) $u_{i}^{\prime}\left(c_{i t}\right) \geq \beta_{i} u_{i}^{\prime}\left(c_{i t+1}\right)\left[1-\delta+g_{k}^{\prime}\left(r_{t+1} k_{i t+1}\right) r_{t+1}\right]$, with equality when $k_{i t+1}>$ 0

(P5) $c_{i t}+k_{i t+1}-(1-\delta) k_{i t}=g_{k}\left(r_{t} k_{i t}\right)+g_{l}\left(w_{t} l_{i t}\right)$;

(P6) $K_{t}=\sum_{i=1}^{2} n_{i} k_{i t}$;

(P7) $L_{t}=\sum_{i=1}^{2} n_{i} l_{i t}$;

(P8) $G_{t}=Y_{t}-\sum_{i=1}^{2}\left[g_{k}\left(r_{t} k_{i t}\right)+g_{l}\left(w_{t} l_{i t}\right)\right] n_{i}$.

Then, if the sequence $\left(r_{t}, w_{t}, K_{t}, L_{t}, Y_{t}, G_{t},\left(k_{i t}, l_{i t}, c_{i t}\right)_{i=1}^{2}\right)_{t=0}^{\infty}$ is a competitive equilibrium, the conditions (P1)-(P8) hold. Moreover, if the sequence $\left(r_{t}, w_{t}, K_{t}, L_{t}, Y_{t}, G_{t},\left(k_{i t}, l_{i t}, c_{i t}\right)_{i=1}^{2}\right)_{t=0}^{\infty}$ satisfies (P1)-(P8) and the transversality condition

$$
\lim _{t \rightarrow+\infty} \beta_{i}^{t} u_{i}^{\prime}\left(c_{i t}\right) k_{i t+1}=0
$$

for $i=1,2$, it is an equilibrium for the economy $E$.

Proof. See the Appendix.

Note that, using homogeneity of degree one of the production function, the first order conditions for profit maximization can also be written:

$$
\begin{aligned}
r_{t} & =f^{\prime}\left(k_{t}\right) \equiv r\left(k_{t}\right) \\
w_{t} & =f\left(k_{t}\right)-k_{t} f^{\prime}\left(k_{t}\right) \equiv w\left(k_{t}\right)
\end{aligned}
$$

Using $f(k) \equiv F(k, 1)$, we obtain the capital share in total income $s(k)$ and the elasticity of capital-labor substitution $\sigma(k)$ :

$$
\begin{aligned}
s(k) & \equiv \frac{k f^{\prime}(k)}{f(k)} \\
\sigma(k) & \equiv[s(k)-1] \frac{f^{\prime}(k)}{k f^{\prime \prime}(k)}
\end{aligned}
$$

Then, the equilibrium prices elasticities can be defined by:

$$
\left(\varepsilon_{r}, \varepsilon_{w}\right) \equiv\left(\frac{k r^{\prime}(k)}{r(k)}, \frac{k w^{\prime}(k)}{w(k)}\right)=\left(-\frac{1-s(k)}{\sigma(k)}, \frac{s(k)}{\sigma(k)}\right)
$$

Before studying steady states, we will prove that the autarkic equilibrium is ruled out.

Proposition 2 Let an economy $E$ satisfy Assumptions 1-3 and $K_{0}>0$. The intertemporal equilibrium is such that, for $t=0, \ldots,+\infty$ :

(i) $K_{t}>0$;

(ii) $c_{i t}>0$, for $i=1,2$;

(iii) $l_{i t}<1$, for $i=1,2$.

Proof. See the Appendix. 


\section{Steady state}

Using some previous results, we first prove the following:

Lemma 1 Under Assumptions 1-3 and $K_{0}>0$, the economy $E$ has no autarkic steady state. Either the most patient households $(i=1)$ own capital $(0<$ $\left.k_{1}=K / n_{1}\right)$, or all households share the capital stock $\left(k_{1}>0, k_{2}>0, K=\right.$ $\left.n_{1} k_{1}+n_{2} k_{2}\right)$. Most patient consumers always hold more capital than impatient ones $\left(k_{1}>k_{2}\right)$.

Proof. See the Appendix.

As a direct implication, two types of steady states could exist depending on the capital distribution: first, steady states where only the most patient households own capital and second, steady states where all consumers share the capital stock. We analyze now the first type of steady states.

Proposition 3 Under Assumptions 1-3 and $K_{0}>0$, there exists a steady state, with constant prices $r$ and $w$, defined by the following properties:

(T1) $u_{1}^{\prime}\left(c_{1}\right) g_{l}^{\prime}\left(w l_{1}\right) w \leq v_{1}^{\prime}\left(1-l_{1}\right)$ and $u_{2}^{\prime}\left(c_{2}\right) g_{l}^{\prime}\left(w l_{2}\right) w=v_{2}^{\prime}\left(1-l_{2}\right)$, i.e., $0 \leq l_{1}<1$ and $0<l_{2}<1$;

(T2) $\beta_{1}\left[1-\delta+g_{k}^{\prime}\left(r k_{1}\right) r\right]=1 \geq \beta_{2}\left[1-\delta+g_{k}^{\prime}(0) r\right]$, i.e., $k_{1}>0$ and $k_{2}=0$;

(T3) $c_{1}=g_{k}\left(r k_{1}\right)-\delta k_{1}+g_{l}\left(w l_{1}\right)>0$ and $c_{2}=g_{l}\left(w l_{2}\right)>0$;

(T4) $K=n_{1} k_{1}>0$;

(T5) $L=\sum_{i=1}^{2} n_{i} l_{i}>0$;

(T6) $Y=F\left(n_{1} k_{1}, L\right)$;

(T7) $G=Y-g_{k}\left(r k_{1}\right) n_{1}-\sum_{i=1}^{2} g_{l}\left(w l_{i}\right) n_{i}$.

Proof. See the Appendix.

By direct inspection of (T1), we see that when most impatient household do not hold capital, two types of steady state can exist, depending on the fact that most patient consumers have or not a strictly positive labor supply $\left(l_{1}=0\right.$ or $\left.l_{1}>0\right)$.

Let $\gamma_{i} \equiv 1 / \beta_{i}-1+\delta$, for $i=1,2$. Condition (T2) means that the equilibria considered in Proposition 3 are characterized by a sufficiently low interest rate $r \leq \gamma_{2} / g_{k}^{\prime}(0)$. We will see in the next proposition that, on the contrary, when the interest rate is sufficiently high, i.e. $r>\gamma_{2} / g_{k}^{\prime}(0)$, there exists steady state such that all the consumers hold capital. In order to prove this result, we further assume:

\section{Assumption 4}


(i) $\lim _{y_{k} \rightarrow+\infty} g_{k}^{\prime}\left(y_{k}\right) y_{k}^{\alpha}=A$, where $A>0$ and $\alpha \in(0,1)$ are constant;

(ii) $g_{k}^{\prime \prime}\left(y_{k}\right)<0$ for all $y_{k}>0$.

Using this additional assumption, we show ${ }^{11}$ :

Proposition 4 Under Assumptions 1-4, $K_{0}>0$ and $g_{k}^{\prime}(0) r>\gamma_{2}$, there exists a steady state, with constant prices $r$ and $w$, defined by the following properties:

(S1) $u_{i}^{\prime}\left(c_{i}\right) g_{l}^{\prime}\left(w l_{i}\right) w \leq v_{i}^{\prime}\left(1-l_{i}\right)$, i.e., $0 \leq l_{i}<1$, for $i=1,2$;

(S2) $1=\beta_{i}\left[1-\delta+g_{k}^{\prime}\left(r k_{i}\right) r\right]$, i.e., $k_{i}>0$, for $i=1,2$;

(S3) $c_{i}=g_{k}\left(r k_{i}\right)-\delta k_{i}+g_{l}\left(w l_{i}\right)>0$, for $i=1,2$;

(S4) $K=\sum_{i=1}^{2} n_{i} k_{i}>0$;

(S5) $L=\sum_{i=1}^{2} n_{i} l_{i}>0$;

(S6) $Y=F(K, L)$;

(S7) $G=Y-\sum_{i=1}^{2}\left[g_{k}\left(r k_{i}\right)+g_{l}\left(w l_{i}\right)\right] n_{i}$. and

if the inequality $n_{1} \underline{k}_{1}<\bar{K}$ is satisfied, with $\bar{K} \equiv \underline{L}\left(f^{\prime}\right)^{-1}(\underline{r}), \underline{r} \equiv \gamma_{2} / g_{k}^{\prime}(0)$

$$
\underline{k}_{1} \equiv\left(g_{k}^{\prime}\right)^{-1}\left(g_{k}^{\prime}(0) \gamma_{1} / \gamma_{2}\right) g_{k}^{\prime}(0) / \gamma_{2}
$$

Proof. See the Appendix.

Note that since $L>0$ (see (S5)), at least one type of households has a strictly positive labor supply $\left(l_{1}>0\right.$ and/or $\left.l_{2}>0\right)$. Considering the case without heterogeneity in the instantaneous utility functions, i.e. $u_{i}\left(c_{i}\right)=u\left(c_{i}\right)$ and $v_{i}\left(1-l_{i}\right)=v\left(1-l_{i}\right)$ for $i=1,2$, we will explain that impatient households always supply more labor $\left(l_{2}>l_{1} \geq 0\right)$.

Note first that if $l_{2}=0$, we have $u^{\prime}\left(c_{2}\right) g_{l}^{\prime}(0) w \leq v^{\prime}(1)$, which implies $u^{\prime}\left(c_{1}\right) g_{l}^{\prime}(0) w<v^{\prime}(1)$ because $k_{1}>k_{2}$ (see Lemma 1) and, hence, $c_{1}>c_{2}$. In other words, $l_{2}=0$ implies $l_{1}=0$, which is ruled out by Proposition 4 . However, the opposite implication does not hold, i.e. equilibria with $l_{2}>0=l_{1}$, cannot be excluded.

Suppose now that all households supply labor $\left(l_{i}>0\right.$ for $\left.i=1,2\right)$. Then, the equality $u^{\prime}\left(c_{i}\right) g_{l}^{\prime}\left(w l_{i}\right) w=v^{\prime}\left(1-l_{i}\right)$ holds for $i=1,2$, where $c_{i}$ is given by (S3). Taking as given the real prices $r$ and $w$, one can easily prove that $l_{i}$ is decreasing in $k_{i}$. We deduce that, when the individuals share the same utility functions $u$ and $v, l_{2}>l_{1} \geq 0 .{ }^{12}$

\footnotetext{
${ }^{11}$ This proposition extends the result by Sarte (1997) to the case where labor supply is endogenous and tax rates on labor and capital incomes are differentiable.

${ }^{12}$ Obviously, this result still holds under a weak degree of heterogeneity in the felicity functions $u_{i}$ and $v_{i}$.
} 
Let us now define the impatient agents' labor supply when $k_{2 t}=0$. The consumption-leisure arbitrage of an impatient agent is given by:

$$
u_{2}^{\prime}\left(c_{2 t}\right) g_{l}^{\prime}\left(w_{t} l_{2 t}\right) w_{t}=v_{2}^{\prime}\left(1-l_{2 t}\right)
$$

Around the steady state where workers hold no capital, the consumption of an impatient agent is simply given by his disposable labor income, i.e. $c_{2 t}=$ $g_{l}\left(w_{t} l_{2 t}\right)$. Using (14), we get:

$$
u_{2}^{\prime}\left(g_{l}\left(w_{t} l_{2 t}\right)\right) g_{l}^{\prime}\left(w_{t} l_{2 t}\right) w_{t}=v_{2}^{\prime}\left(1-l_{2 t}\right)
$$

Because one takes into account that consumption only depends on the labor income, this implicitly gives the labor supply as a function of the real wage, $l_{2 t}=l_{2}\left(w_{t}\right)$. The assumptions on technology, preferences and taxation ensure a correct definition of this function:

Lemma 2 If Assumptions 1-2 are satisfied, then the labor supply $l_{2 t}=l_{2}\left(w_{t}\right)$ is a well-defined function.

Proof. See the Appendix.

Differentiating (15), and using (3) and (6), we are able to determine the impatient agents' elasticity of labor supply $\varepsilon_{2} \equiv w l_{2}^{\prime}(w) / l_{2}(w)$ :

$$
\varepsilon_{2} \equiv \frac{1+\omega_{22}-\frac{\omega_{12}}{\sigma_{12}}}{\frac{\omega_{12}}{\sigma_{12}}-\omega_{22}+\frac{l_{2}}{1-l_{2}} \frac{1}{\sigma_{22}}}
$$

Notice that this elasticity is strictly negative under a sufficiently weak elasticity of intertemporal substitution in consumption $\sigma_{12}$ and/or if the elasticity of disposable labor income $\left|\omega_{12}\right|$ is large enough.

To provide now a sufficient condition for the uniqueness of a steady state characterized by $k_{1}>0=k_{2}$, which applies to both the cases where $l_{1}=0$ and $l_{1}>0$. For $i=1,2$, let:

$$
\tilde{\varepsilon}_{i} \equiv-\frac{\frac{1}{\sigma_{1 i}} \frac{1-s}{s} \frac{\gamma_{i}-\left(1+\rho_{2 i}\right) \delta}{\rho_{2 i}} \frac{k_{i}}{c_{i}}-\Omega_{i}}{1+\frac{1}{\sigma_{2 i}} \frac{l_{i}}{1-l_{i}}-\Omega_{i}}
$$

with

$$
\Omega_{i} \equiv 1+\omega_{2 i}-\frac{\omega_{1 i}}{\sigma_{1 i}}\left[1-\frac{k_{i}}{c_{i}}\left(\frac{\gamma_{i}}{\rho_{1 i}}-\delta\right)\right]
$$

Corollary 1 Let $\lambda_{1} \equiv n_{1} l_{1} / L \in[0,1), \lambda_{2} \equiv n_{2} l_{2} / L \in(0,1]$. Under Assumptions 1-3 and $K_{0}>0$, there exists a unique steady state, with constant prices $r$ and $w$, defined by $l_{1} \geq 0, l_{2}>0$, and the properties (T1)-(T7), if the following condition holds for all $k>0$ :

$$
\sigma>\sigma_{P_{1}} \equiv s\left[\varepsilon_{P}-\left(\lambda_{1} \tilde{\varepsilon}_{1}+\lambda_{2} \varepsilon_{2}\right)\right]
$$

where $\varepsilon_{P} \equiv(1-s)\left(1+\rho_{21}\right) /\left(s \rho_{21}\right), \varepsilon_{2}$ is given by (16), and $\tilde{\varepsilon}_{1}$ by (17). 
Proof. See the Appendix.

Note that in the case where patient households do not supply labor, i.e. $l_{1}=0$, inequality (18) applies with $\lambda_{1}=0$ and $\lambda_{2}=1$. We now provide a similar result for steady state with $k_{1}>0$ and $k_{2}>0$.

Corollary 2 Let $\lambda_{i} \equiv n_{i} l_{i} / L$ and $\kappa_{i} \equiv n_{i} k_{i s}(r) / \sum_{j=1}^{2} n_{j} k_{j s}(r)$, where $k_{i s}(r) \equiv$ $\left(g_{k}^{\prime}\right)^{-1}\left(\gamma_{i} / r\right) / r$, for $i=1,2$. Under Assumptions 1-4, $K_{0}>0, g_{k}^{\prime}(0) r>\gamma_{2}$ and $n_{1} \underline{k}_{1}<\bar{K}$, there exists a unique steady state, with constant prices $r$ and $w$, defined by either $l_{1}>0$ or $l_{2}>0$, and the properties (S1)-(S7), if the following condition holds for all $r>\underline{r}$ :

$$
\sigma>\sigma_{P_{2}} \equiv(1-s) \sum_{i=1}^{2} \frac{1+\rho_{2 i}}{\rho_{2 i}} \kappa_{i}-s\left(\lambda_{1} \tilde{\varepsilon}_{1}+\lambda_{2} \tilde{\varepsilon}_{2}\right)
$$

Proof. See the Appendix.

Corollaries 1 and 2 establish the conditions for the uniqueness of the steady state when, respectively, capital is only supplied by the most patient households or supplied by all consumers. Obviously, as soon as these conditions are violated, a multiplicity of solutions can emerge, keeping in mind that the number of steady states is generically odd. Especially, this will arise if, in both cases, $\sigma<\sigma_{P_{j}}$, $j=1,2$, at a stationary solution. ${ }^{13}$

By direct inspection of $\sigma_{P_{j}}, j=1,2$, we note that marginal progressivity in capital taxation $\left(\rho_{2 i}<0\right)$ plays a crucial role on the number of steady states. Indeed, if $\rho_{2 i}$ tends to 0 , uniqueness is ensured because $\sigma_{P_{i}}$ becomes negative. ${ }^{14}$

It is also interesting to notice that endogenous labor supply has an important impact on the uniqueness versus multiplicity. Indeed, in the case of inelastic labor supply $\left(\sigma_{2 i}=0\right), \sigma_{P_{j}}$ only depends on $\rho_{2 i},{ }^{15}$ i.e. on capital taxation. Hence, $\sigma_{P_{1}}\left(\sigma_{P_{2}}\right)$ is strictly positive only if $\rho_{21}$ (at least one $\left.\rho_{2 i}, i=1,2\right)$ is strictly smaller than -1 . When labor supply is elastic $\left(\sigma_{2 i}>0\right)$, marginal progressivity on labor taxation $\left(\omega_{2 i}\right)$ and the degrees of intertemporal substitution $\left(\sigma_{j i}\right)$ also affect the results. In particular, when the marginal progressivity of labor tax rates is large enough, a strictly positive value of $\sigma_{P_{i}}$ can occur for $\rho_{2 i}>-1$. In this case, if capital tax rate has also a sufficiently large marginal progressivity, $\sigma_{P_{j}}$ can take positive values not so close to $0 .{ }^{16}$

The possible existence of multiple stationary solutions matters from an individual point of view. Let us focus on steady states where both the types hold a positive amounts of capital, i.e. $k_{1}, k_{2}>0$ (see Proposition 4 and Corollary

\footnotetext{
${ }^{13}$ We observe that, according to the proofs of Corollaries 1 and $2, \sigma$ can never be smaller than $\sigma_{P_{i}}$ for all $k$.

${ }^{14}$ Recall also that, from Assumption 4, a strictly negative value of $\rho_{2 i}$ is needed to ensure the existence of a steady state where all households supply a positive amount of capital.

${ }^{15}$ For $\sigma_{2 i}=0$, we get $\sigma_{P_{1}}=(1-s)\left(1+1 / \rho_{21}\right)$ and $\sigma_{P_{2}}=(1-s) \sum_{i=1}^{2}\left(1+1 / \rho_{2 i}\right) \kappa_{i}$.

${ }^{16}$ According to Corollaries 1 and 2 , when $\omega_{2 i}$ tends to $+\infty$, we obtain $\sigma_{P_{1}}=1+(1-s) / \rho_{21}$ and $\sigma_{P_{2}}=1+(1-s) \sum_{i=1}^{2} \kappa_{i} / \rho_{2 i}$.
} 
$2)$. The steady states can be ranked according to their level of real interest rate $r$. Moreover, $k_{i} \equiv k_{i s}(r)$ is defined by (64) (see the Appendix), where $k_{i s}^{\prime}(r) r / k_{i s}(r)=-\left(1+1 / \rho_{2 i}\right)$. From Lemma 1 , we know that $k_{1}>k_{2}$, whatever the steady state and the associated level of $r$. However, in order to understand how wealth inequality evolves with the steady state considered, that is how it changes in response to the interest rate $r$, we compute the following difference:

$$
\frac{k_{1 s}^{\prime}(r) r}{k_{1 s}(r)}-\frac{k_{2 s}^{\prime}(r) r}{k_{2 s}(r)}=\frac{1}{\rho_{2}\left(r k_{2}\right)}-\frac{1}{\rho_{2}\left(r k_{1}\right)}
$$

where $\rho_{2 i} \equiv \rho_{2}\left(r k_{i}\right)$ by definition. ${ }^{17}$

Therefore, if the function $\rho_{2}\left(r k_{i}\right)$ is increasing, the wealth inequality raises, whereas we get the converse if $\rho_{2}\left(r k_{i}\right)$ is decreasing. In other terms, wealth inequality is larger in a steady state characterized by a larger interest rate $r$ if the degree of marginal progressivity $\left|\rho_{2}\left(r k_{i}\right)\right|$ is decreasing.

Suppose now that all households have a strictly positive labor supply. Using (S1) and (S3), one can implicitly define $l_{i}$ as a function of $r .{ }^{18}$ Then, one can prove that $l_{i}$ is increasing in $r$ if $\sigma_{1 i}$ and $\rho_{2 i}$ are weak enough. In other words, each individual labor supply turns out to be larger in a steady state characterized by a higher level of real interest rate $r$. Unfortunately, it is difficult to establish a relationship between the difference of labor supplies and the interest rate and, hence, provide a clear-cut conclusion on the impact of the level of the steady state on income inequality.

\section{Comparative statics}

In this section, we focus on steady states where the most patient households hold the whole capital stock and supply no labor, i.e. $k_{1}>k_{2}=0$ and $l_{2}>l_{1}=0$ (see Proposition 3). ${ }^{19}$ This type of equilibria is of interest because the population endogenously splits in two classes, (patient) capitalists who hold the whole capital stock and do not supply labor, and (impatient) workers who do not save and are the only ones who supply labor (see also Bosi and Seegmuller (2007)). This also provides some foundations of the models developed by Mankiw (2000), Michel and Pestieau (1999) and Woodford (1989). ${ }^{20}$

We start by analyzing how the population sizes of patient/impatient agents in total population affect the steady state allocation. In a second part, we will study the impact of a modification of the level of the tax rates.

\footnotetext{
${ }^{17}$ Taxation is not ad personam and, therefore, the functional form $\rho_{2}$ is type-independent (see $(5))$.

${ }^{18}$ See also the proof of Corollary 2.

${ }^{19}$ Such a stationary equilibrium where a part of population is constrained by some borrowing restrictions and consumes his current disposable income is in accordance with several empirical results. See for instance Bacchetta and Gerlach (1997) or Cushing (1992). For a critical survey, see Attanasio (1999).

${ }^{20}$ Note that Thibault (2005) has developed a explanation of population segmentation closely related to ours using an overlapping generations model with heterogeneous altruistic agents.
} 


\subsection{Effects of population sizes}

Recall that (T1) and (T3) in Proposition 3 implicitly define $l_{2}$ as a function of $k$, $l_{2} \equiv l_{2}(k)$, with an elasticity $\varepsilon_{2} s / \sigma .{ }^{21}$ Set $H(k, \nu) \equiv g_{k}^{\prime}\left[k f^{\prime}(k) l_{2}(k) / \nu\right] f^{\prime}(k)$, where $\nu \equiv n_{1} / n_{2}$ denotes the relative magnitude of social classes. In line with the proofs of Proposition 3 and Corollary 1, we obtain the steady states as solutions of:

$$
H(k, \nu)=\gamma_{1}
$$

In particular, the steady state is unique if:

$$
\varepsilon_{H k} \equiv \frac{k}{H} \frac{\partial H}{\partial k}=\rho_{21}\left[1+\frac{s}{\sigma} \varepsilon_{2}-\frac{1+\rho_{21}}{\rho_{21}} \frac{1-s}{\sigma}\right]<0
$$

for every $k>0$, or, equivalently, $\sigma>(1-s)\left(1+1 / \rho_{21}\right)-s \varepsilon_{2}=\sigma_{P_{1}}$, as seen in Corollary 1.

The population sizes $n_{1}$ and $n_{2}$ can affect the aggregate variables in the model. The next proposition summarizes the effects on the aggregate capital $K$ :

Proposition 5 Under Assumptions 1-3 and $K_{0}>0$, if $\varepsilon_{H k}<0$, the following holds:

(i) The aggregate capital $K$ is increasing (decreasing) in the number of patient agents $n_{1}$ if $\sigma>-s \varepsilon_{2}\left(\sigma<-s \varepsilon_{2}\right)$, where $\varepsilon_{2}$ is defined by (16);

(ii) $K$ is increasing in the number of impatient agents $n_{2}$ if $\rho_{21}>-1$.

The converse holds if $\varepsilon_{H k}>0$.

Proof. See the Appendix.

We study now the effects on the production $Y$ :

Proposition 6 Under Assumptions 1-3 and $K_{0}>0$. If $\varepsilon_{H k}<0$, the following holds:

(i) $Y$ is increasing (decreasing) in $n_{1}$ if $\sigma>-\varepsilon_{2}\left(\sigma<-\varepsilon_{2}\right)$, where $\varepsilon_{2}$ is defined by (16);

(ii) $Y$ is increasing (decreasing) in $n_{2}$ if $\sigma>1+1 / \rho_{21}\left(\sigma<1+1 / \rho_{21}\right)$.

If $\varepsilon_{H k}>0$, we get the reverse effects.

Proof. See the Appendix.

Note that when labor supply is inelastic $\left(\sigma_{22}=0\right)$, the critical value $-\varepsilon_{2}$ becomes equal to zero. On the contrary, for $\sigma_{22}>0,-\varepsilon_{2}$ increases with $\omega_{12} / \sigma_{12}$,

\footnotetext{
${ }^{21}$ See equation (69) in the proof of Corollary 1.
} 
and tends to 1 when this ratio tends to $+\infty$, i.e. when the elasticity of intertemporal substitution in consumption $\sigma_{12}$ tends to 0 and/or the elasticity of labor income $\left|\omega_{12}\right|$ tends to $+\infty$.

Since we consider a steady state with $k_{1}>k_{2}=0$ and $l_{2}>l_{1}=0$, the individual incomes of households of type 1 and 2 are respectively given by:

$$
\begin{aligned}
I_{1}(k, \nu) & \equiv g_{k}\left(r(k) k l_{2}(k) / \nu\right) \\
I_{2}(k) & \equiv g_{l}\left(w(k) l_{2}(k)\right)
\end{aligned}
$$

We now analyze the influence of the population sizes $n_{1}$ and $n_{2}$ on these incomes. A direct inspection of (20), (22) and (23) will persuade us that the relative size $\nu$ is what actually matters.

Proposition 7 Under Assumptions 1-3 and $K_{0}>0$, an increase in the relative number of patient households $\nu$ has the following effect on the households' individual income. If $\varepsilon_{H k}<0$, we get:

(i) a decrease of the patient households' individual income $I_{1}$;

(ii) an increase of the impatient households' individual income $I_{2}$.

If $\varepsilon_{H k}>0$, we get the reverse effects.

Proof. See the Appendix.

Finally, we characterize the impact of population shares on the welfare evaluated at the steady state.

Focus first on patient agents. For the sake of simplicity, assume the capital depreciation rate sufficiently close to zero $(\delta \approx 0)$. In this case, $W_{1}=$ $\left[u_{1}\left(I_{1}\right)+v_{1}(1)\right] /\left(1-\beta_{1}\right)$ and the impact of $\nu$ on $W_{1}$ is similar to that on $I_{1}$ we have characterized above (point (i) of Proposition 7 ).

The next proposition characterizes the impact of the population shares on the welfare of impatient agents $W_{2} \equiv\left[u_{2}\left(c_{2}\right)+v_{2}\left(1-l_{2}\right)\right] /\left(1-\beta_{2}\right)$.

Proposition 8 Under Assumptions 1-3 and $K_{0}>0$, an increase of the relative number of patient households $\nu$ raises welfare $W_{2}$ iff $\varepsilon_{H k}<0$.

Proof. See the Appendix.

\subsubsection{Interpretation}

In the following, we focus on the simplest case where $\varepsilon_{H k}<0$, that applies when the marginal progressivity on capital is sufficiently weak or the elasticity of capital-labor substitution high enough. We begin by considering the modified golden rule $H(k, \nu)=\gamma_{1}$, which implies $\varepsilon_{H k} d k / k-\rho_{21} d \nu / \nu=0$. Then, $k$ has a negative impact on the return on capital, while the relative density of capitalists $\nu$ reduces their individual income and increases the marginal rate of taxation. This implies a positive impact of $\nu$ on $k: \rho_{21} / \varepsilon_{H k}>0$. It is also important to 
note that the relative share of population sizes affects the capital-labor ratio, because of the marginal progressivity of the tax rule on capital income. In the case of a flat tax on capital income $\left(\rho_{21}=0\right)$, a modification of the population sizes does not affect $k$.

Consider the aggregate capital stock $K=n_{2} k l_{2}(k)$. Since $d K / K=d n_{2} / n_{2}+$ $\left(1+\varepsilon_{2} s / \sigma\right) d k / k, n_{2}$ has two effects on $K$. On the one hand, $n_{2}$ has a direct positive impact, because, given the capital per worker, the aggregate capital depends on the number of workers. On the other hand, $n_{2}$ reducing the capital per worker according to $d k / k=\left(\rho_{21} / \varepsilon_{H k}\right) d \nu / \nu$ and then the real wage, has a negative impact on $K$ if the elasticity of labor supply is not too negative $\left(\varepsilon_{2}>-\sigma / s\right)$. The population size of patient agents $n_{1}$ has no direct effect on $K$, but only through $k$. Its impact is the same as $\nu$, that is, the opposite one to the previous effect of $n_{2}$ on $k$.

We focus now on the aggregate income $Y=n_{2} f(k) l_{2}(k)$, where $d Y / Y=$ $d n_{2} / n_{2}+s\left(1+\varepsilon_{2} / \sigma\right) d k / k$. The population size $n_{2}$ still has a direct positive impact, but now the indirect impact through $k$ is negative iff $\varepsilon_{2}>-\sigma$, which remains a plausible condition, even if it is more restrictive. As above, $n_{1}$ has only an indirect effect through $k$, which is opposite to the indirect effect of $n_{2}$.

Considering the individual income of a patient household $I_{1} \equiv g_{k}\left(r(k) k l_{2}(k)\right.$ $/ \nu)$, the relative density of capitalists $\nu$ has a direct negative impact on the (pre-tax) capital income per capitalist. However, as seen above above, $\nu$ has a positive impact on the capital intensity $k$ and, therefore, can positively affect $r(k) k l_{2}(k)$. However, even in this case, the first effect dominates reducing the income $I_{1}$.

Consider the workers' income $I_{2} \equiv g_{l}\left(w(k) l_{2}(k)\right)$. The relative density of capitalists $\nu$ has only an indirect impact on $I_{2}$ through $k$. Since the relationship between $k$ and $\nu$ is positive, the effect on the pre-tax labor income $w(k) l_{2}(k)$ is positive because the increase of the real wage dominates the possible decrease of the labor supply. Note however that, without progressivity on the capital tax rule $\left(\rho_{21}=0\right)$, the labor income is independent of the population sizes.

The impact of the income $I_{2}$ on the workers' welfare measure $W_{2}$ is positive, while that of labor supply $l_{2}$ is negative. The effects of $\nu$ on $I_{2}$ and $l_{2}$, both depend on the elasticity of labor supply $\varepsilon_{2}$, but these ambiguities cancel out each other when we compute the aggregate effect of $\nu$ on $W_{2}$ (see equation (81) in the Appendix), which turns out to be positive (equation (82)).

\subsection{Effects of tax rates}

In order to capture the effects of the tax rates on the stationary allocation, we assume that taxes have a linear specification:

$$
\tau_{h}\left(y_{h}\right) \equiv t_{h} y_{h}+T_{h}
$$

with $t_{h} \in[0,1), T_{h} \geq 0, h=k, l$. Notice that $y_{k} \equiv r k_{1}=r k l_{2} n_{2} / n_{1}, y_{l}=w l_{2}$ and $c_{2}=\left(1-t_{l}\right) y_{l}-T_{l}$. The specification (24) allows us to take in account either distortionary or lump-sum taxes and implies the following disposable incomes, 
for $h=k, l$ :

$$
g_{h}\left(y_{h}\right)=\left(1-t_{h}\right) y_{h}-T_{h}
$$

In order to make expression (24) compatible with Assumption 2 when $T_{h}>0$, we further assume that the linearity in taxation holds in a neighborhood of the steady state. In any case, $T_{h}$ has to be sufficiently small in order to ensure a positive disposable income: $T_{h}<\left(1-t_{h}\right) y_{h}$. For further reference, let:

$$
\begin{aligned}
q_{1} & \equiv \frac{\left(1-t_{k}\right) y_{k}-T_{k}}{\left(1-t_{k}\right) y_{k}} \in(0,1] \\
q_{2} & \equiv \frac{\left(1-t_{l}\right) y_{l}-T_{l}}{\left(1-t_{l}\right) y_{l}} \in(0,1]
\end{aligned}
$$

Moreover, since $\omega_{22}=0$, the elasticity of labor supply $\varepsilon_{2}$ (see equation (16)) simplifies to:

$$
\varepsilon_{2}=\frac{q_{2}-\frac{1}{\sigma_{12}}}{\frac{1}{\sigma_{12}}+\frac{q_{2}}{\sigma_{22}} \frac{l_{2}}{1-l_{2}}}
$$

The tax rate on capital introduces a distortion in the modified golden rule, but preserves the uniqueness of the steady state:

$$
\left(1-t_{k}\right) f^{\prime}(k)=\gamma_{1}
$$

More precisely, among the fiscal parameters, only the proportional tax rate $t_{k}$ affects the capital-labor ratio and the impact is negative:

$$
\frac{\partial k}{\partial t_{k}} \frac{t_{k}}{k}=-\frac{\sigma}{1-s} \frac{t_{k}}{1-t_{k}}<0
$$

More explicitly, when the tax rate $t_{k}$ increases, the after-tax real interest rate decreases. Therefore, to stay at the modified golden rule, the marginal productivity should increase, which in turn implies a reduction of the capitallabor ratio. Moreover, using (T1), (T3) of Proposition 3, equation (25) and applying the implicit function theorem, we locally define $l_{2} \equiv l_{2}\left(k, T_{l}, t_{l}\right) .^{22}$

Let us start by analyzing the effect of taxes on the aggregate variables $K$ and $Y$. Using the fact that $K=k n_{2} l_{2}\left(k, T_{l}, t_{l}\right)$, we get the following proposition:

Proposition 9 Under Assumptions 1-3, $K_{0}>0$ and (25), the following holds:

(i) $K$ does not depend on $T_{k}$;

(ii) $K$ is increasing in $T_{l}$;

(iii) $K$ is increasing (decreasing) in $t_{k}$ if $\sigma<-s \varepsilon_{2}\left(\sigma>-s \varepsilon_{2}\right)$;

(iv) $K$ is increasing (decreasing) in $t_{l}$ if $\varepsilon_{2}<0\left(\varepsilon_{2}>0\right)$.

\footnotetext{
${ }^{22}$ See the Appendix for more details.
} 
Proof. See the Appendix.

Using $Y=f(k) n_{2} l_{2}\left(k, T_{l}, t_{l}\right)$, we are able to analyze the effects of taxation on the aggregate production:

Proposition 10 Under Assumptions 1-3, $K_{0}>0$ and (25), the following holds:

(i) $Y$ does not depend on $T_{k}$;

(ii) $Y$ is increasing in $T_{l}$;

(iii) $Y$ is increasing (decreasing) in $t_{k}$ if $\sigma<-\varepsilon_{2}\left(\sigma>-\varepsilon_{2}\right)$;

(iv) $Y$ is increasing (decreasing) in $t_{l}$ if $\varepsilon_{2}<0\left(\varepsilon_{2}>0\right)$.

Proof. See the Appendix.

We now analyze the effects of the tax rules on economic variables relevant at the individual level, i.e. on the income distribution and consumers' welfare, evaluated at the steady state. As in the previous section, we define $I_{1} \equiv g_{k}\left(r(k) k_{1}\right)$ and $I_{2} \equiv g_{l}\left(w(k) l_{2}\right)$. Using (25), we obtain $I_{1}=$ $\left(1-t_{k}\right) r(k) k l_{2}\left(k, T_{l}, t_{l}\right) n_{2} / n_{1}-T_{k}$ and $I_{2}=\left(1-t_{l}\right) w(k) l_{2}\left(k, T_{l}, t_{l}\right)-T_{l}$.

The following proposition summarizes the impact of a variation of the tax rates on the individual income of a patient household:

Proposition 11 Under Assumptions 1-3, $K_{0}>0$ and (25), the following holds:

(i) $I_{1}$ is decreasing in $T_{k}$;

(ii) $I_{1}$ is increasing in $T_{l}$;

(iii) $I_{1}$ is increasing (decreasing) in $t_{k}$ if $\sigma<-s \varepsilon_{2}\left(\sigma>-s \varepsilon_{2}\right)$;

(iv) $I_{1}$ is increasing (decreasing) in $t_{l}$ if $\varepsilon_{2}<0\left(\varepsilon_{2}>0\right)$.

Proof. See the Appendix.

We observe that, evaluated at the steady state, the welfare of a patient household is given by $W_{1} \equiv\left[u_{1}\left(c_{1}\right)+v_{1}(1)\right] /\left(1-\beta_{1}\right)$, with $c_{1}=I_{1}-\delta K / n_{1}$. Because $W_{1}$ is increasing in $c_{1}$, for a depreciation rate of capital $\delta$ sufficiently close to zero, the effects of a modification of tax rules on the welfare of a patient household are also given by Proposition 11 .

We now analyze the effects of taxes on the individual income of an impatient household.

Proposition 12 Under Assumptions 1-3, $K_{0}>0$ and (25), the following holds:

(i) $I_{2}$ does not depend on $T_{k}$;

(ii) $I_{2}$ is decreasing in $T_{l}, t_{k}$ or $t_{l}$. 
Proof. See the Appendix.

Since $c_{2}=I_{2}$, Proposition 12 also describes the effects of tax rules on the consumption of impatient households. However, since they elastically supply labor, the impact on their welfare $W_{2} \equiv\left[u_{2}\left(c_{2}\right)+v_{2}\left(1-l_{2}\right)\right] /\left(1-\beta_{2}\right)$ should be analyzed more carefully. The results are summarized in the next proposition:

Proposition 13 Under Assumptions 1-3, $K_{0}>0$ and (25), the following holds:

(i) $W_{2}$ does not depend on $T_{k}$;

(ii) $W_{2}$ is decreasing in $T_{l}, t_{k}$ or $t_{l}$.

Proof. See the Appendix.

\subsubsection{Interpretation}

First, consider the impact of the lump-tax on capital $T_{k}$. Since it affects only the capitalists' after-tax income $I_{1}$ and has no effect on the capital-labor ratio $k$, then $K, Y, I_{2}$ and $W_{2}$ do not depend on it, while $I_{1}$ and $W_{1}$ are obviously negatively affected.

Focus now on $T_{l}$. The impact on the individual labor supply $l_{2}$ is positive. Indeed, according to the expression of $\left(T_{l} / l_{2}\right) \partial l_{2} / \partial T_{l}$ in (83), given the real wage, workers compensate the reduction of disposable income with a higher labor supply. Since the effects on $K, Y, I_{1}$ only go through $l_{2}$, we get a positive impact of $T_{l}$. However, the impact on $I_{2}=\left(1-t_{l}\right) w l_{2}-T_{l}$ is negative, because the positive impact through $l_{2}$ is dominated by the direct effect $-T_{l}$. Clearly, the effect on $W_{2}$ is negative: the impatient agents work more, but their disposable income lowers.

Third, consider an increase of the distortionary tax $t_{l}$. As above, the effects on $K, Y, I_{1}$ only go through the labor supply $l_{2}$. However, now, the impact on the individual labor supply $l_{2}$ is ambiguous, because the tax is distortionary and a decrease in the after-tax real wage can induce agents to work less. This happens only if the elasticity of labor supply is positive, that is, the elasticity of intertemporal substitution in consumption is sufficiently high and the substitution effect dominates the income effect. Indeed, $\varepsilon_{2}>0$ is equivalent to $\sigma_{12}>1 / q_{2}$. However, the impact on $I_{2}=\left(1-t_{l}\right) w l_{2}\left(k, T_{l}, t_{l}\right)-T_{l}$ is unambiguously negative because the decrease of $1-t_{l}$ always dominates the ambiguous effect of $l_{2}$. Concerning the welfare of impatient agents, when $\varepsilon_{2}>0$, the reduction of disposable income and, therefore, of consumption, is not completely offset by the increase of leisure, which explains that $W_{2}$ decreases. A fortiori, $W_{2}$ decreases when $\varepsilon_{2}<0$, because agents work more.

We finish by analyzing the effects of an increase of $t_{k}$. Only this tax has an impact on the capital intensity $k$, which is negative (see (28) and its immediate interpretation). We observe two effects on the aggregate capital $K=k n_{2} l_{2}\left(k, T_{l}, t_{l}\right): k$ decreases, while, according to (83), $l_{2}$ increases iff $\varepsilon_{2}<0$, 
that is $\sigma_{12}<1 / q_{2}$ (when $k$ decreases, the real wage decreases as well and labor supply increases iff the income effect dominates the substitution effect). Therefore, a positive total impact requires a sufficiently negative elasticity of labor supply: $\varepsilon_{2}<-\sigma / s$. The mechanism is quite similar for the aggregate income $Y=f(k) n_{2} l_{2}\left(k, T_{l}, t_{l}\right)$, but now the condition for a total positive impact becomes less demanding $\left(\varepsilon_{2}<-\sigma\right)$ because of the concavity of $f$.

Concerning the capitalists' income $I_{1}=\left(1-t_{k}\right) r(k) k l_{2}\left(k, T_{l}, t_{l}\right)$, the addition of several effects is still ambiguous. An increase of $t_{k}$ lowers $1-t_{k}$ and $k$, but raises the interest rare $r$ and has on labor supply $l_{2}$ the same effect we highlighted above. The lower the elasticity of capital-labor substitution $\sigma$, the higher the response of interest rate and the lower $\varepsilon_{2}<0$, the larger the positive response of $l_{2}$. This explains why $I_{1}$ increases iff $\sigma<-s \varepsilon_{2}$.

Workers' income $I_{2}=\left(1-t_{l}\right) w(k) l_{2}\left(k, T_{l}, t_{l}\right)$ always diminishes when the fiscal authority raises $t_{k}$, because the decrease of $k$ entails a fall in the real wage, which definitely dominates the ambiguous behavior of labor supply $l_{2}$. The subsequent contraction in consumption lowers their satisfaction level, even if they work less, and this eventually reduces $W_{2}$.

\section{Dynamics}

In this section, we begin to study the stability properties and the occurrence of cycles in the neighborhood of the steady state where patient consumers own the whole capital stock $\left(K_{t}=n_{1} k_{1 t}\right.$ and $\left.k_{2 t}=0\right)$. As explained at the beginning of Section 5, considering such a steady state is relevant from a theoretical as well as an empirical point of view. We start by deriving the pertinent dynamic system.

\subsection{Dynamic system}

The impatient agents' labor supplies have been derived from the arbitrage equation (14). Focus now on the consumption-leisure arbitrage of an agent of type 1 , when labor supply is strictly positive:

$$
u_{1}^{\prime}\left(c_{1 t}\right) g_{l}^{\prime}\left(w_{t} l_{1 t}\right) w_{t}=v_{1}^{\prime}\left(1-l_{1 t}\right)
$$

where

$$
c_{1 t}=g_{k}\left(r_{t} k_{1 t}\right)+g_{l}\left(w_{t} l_{1 t}\right)-k_{1 t+1}+(1-\delta) k_{1 t}
$$

Substituting (30) into (29), the consumption-leisure arbitrage defines a labor supply, which depends on the real wage and individual consumption $l_{1 t} \equiv$ $l_{1}\left(w_{t}, c_{1 t}\right)$.

The following lemma ensures that this labor supply is well-defined:

Lemma 3 If $\lim _{l_{1 t} \rightarrow 0} v_{1}^{\prime}\left(1-l_{1 t}\right)<u_{1}^{\prime}\left(c_{1 t}\right) g_{l}^{\prime}\left(w_{t} l_{1 t}\right) w_{t}$ and Assumptions 1 and 2 are satisfied, then $l_{1 t}=l_{1}\left(w_{t}, c_{i t}\right)$ is a well-defined function. 
Proof. See the Appendix.

For our analysis, it is also useful to derive the aggregate labor supply. Recalling that, around the steady state, $K_{t}=n_{1} k_{1 t}$ and using Lemma 3, (P2) and (P7) of Proposition 3, and equations (9) and (10), we obtain:

$$
L_{t}=n_{1} l_{1}\left(w\left(\frac{n_{1} k_{1 t}}{L_{t}}\right), c_{1 t}\right)+n_{2} l_{2}\left(w\left(\frac{n_{1} k_{1 t}}{L_{t}}\right)\right)
$$

that is, an implicit equation relating the aggregate labor supply $L_{t}$ to the individual capital and consumption: $L_{t} \equiv L\left(k_{1 t}, c_{1 t}\right)$. Therefore, using the notation $\beta \equiv \beta_{1}$, the condition (P4) of Proposition 3, which holds with equality for the most patient agents in the neighborhood of the steady state, writes:

$$
\begin{aligned}
u_{1}^{\prime}\left(c_{1 t}\right)= & \beta u_{1}^{\prime}\left(c_{1 t+1}\right) \\
& {\left[1-\delta+g_{k}^{\prime}\left(r\left(\frac{n_{1} k_{1 t+1}}{L\left(k_{1 t+1}, c_{1 t+1}\right)}\right) k_{1 t+1}\right) r\left(\frac{n_{1} k_{1 t+1}}{L\left(k_{1 t+1}, c_{1 t+1}\right)}\right)\right] }
\end{aligned}
$$

while the patient agents' equilibrium budget constraint becomes:

$$
\begin{aligned}
c_{1 t}= & g_{k}\left(r\left(\frac{n_{1} k_{1 t}}{L\left(k_{1 t}, c_{1 t}\right)}\right) k_{1 t}\right) \\
& +g_{l}\left(w\left(\frac{n_{1} k_{1 t}}{L\left(k_{1 t}, c_{1 t}\right)}\right) l_{1}\left(w\left(\frac{n_{1} k_{1 t}}{L\left(k_{1 t}, c_{1 t}\right)}\right), c_{1 t}\right)\right)-k_{1 t+1}+(1-\delta) k_{1 t}
\end{aligned}
$$

Given the initial condition $k_{10}>0$ and the transversality condition (8), equations (32) and (33) constitute a two-dimensional dynamics that determines the sequence $\left(k_{1 t}, c_{1 t}\right)_{t=0}^{+\infty}$. As usual, $k_{1 t}$ is a predetermined variable, while $c_{1 t}$ jumps in order to implement an equilibrium path, which is positive and compatible with the transversality condition.

As seen above for the impatient agents (equation (16)), we define the elasticity of labor supply. More precisely, differentiating $l_{1}=l_{1}\left(w, c_{1}\right)$ with respect to $w, c_{1}$ and $l_{1}$, and using (3) and (6) gives:

$$
\left(\varepsilon_{1}, \varepsilon_{l_{1} c_{1}}\right) \equiv\left(\frac{w l_{1 w}\left(w, c_{1}\right)}{l_{1}\left(w, c_{1}\right)}, \frac{c_{1} l_{1 c_{1}}\left(w, c_{1}\right)}{l_{1}\left(w, c_{1}\right)}\right)=\left(\frac{1+\omega_{21}}{\frac{l_{1}}{1-l_{1}} \frac{1}{\sigma_{21}}-\omega_{21}},-\frac{\frac{1}{\sigma_{11}}}{\frac{l_{1}}{1-l_{1}} \frac{1}{\sigma_{21}}-\omega_{21}}\right)
$$

Eventually, differentiating $L=L\left(k_{1}, c_{1}\right)$ with respect to $k_{1}, c_{1}$ and $L$, we get the following elasticities:

$$
\left(\varepsilon_{L k_{1}}, \varepsilon_{L c_{1}}\right) \equiv\left(\frac{k_{1} L_{k_{1}}\left(k_{1}, c_{1}\right)}{L\left(k_{1}, c_{1}\right)}, \frac{c_{1} L_{c_{1}}\left(k_{1}, c_{1}\right)}{L\left(k_{1}, c_{1}\right)}\right)=\left(\frac{\varepsilon \varepsilon_{w}}{1+\varepsilon \varepsilon_{w}}, \frac{\lambda_{1} \varepsilon_{l_{1} c_{1}}}{1+\varepsilon \varepsilon_{w}}\right)
$$

where $\varepsilon \equiv \lambda_{1} \varepsilon_{1}+\lambda_{2} \varepsilon_{2}$ is the average elasticity of labor supply with respect to the real wage, with weights $\left(\lambda_{1}, \lambda_{2}\right) \equiv\left(n_{1} l_{1} / L, n_{2} l_{2} / L\right)$. 


\subsection{Preliminaries}

The issue of convergence to the steady state is now addressed through a local analysis. To characterize the stability properties of the steady state and the occurrence of local bifurcations, we proceed by linearizing the dynamic system (32)-(33) around the steady state $\left(k_{1}, c_{1}\right)$ defined in Proposition 3 and computing the Jacobian matrix $J$, evaluated at this steady state. Local dynamics are represented by a linear system $\left(d k_{1 t+1} / k_{1}, d c_{1 t+1} / c_{1}\right)^{T}=J\left(d k_{1 t} / k_{1}, d c_{1 t} / c_{1}\right)^{T}$. In the following, we exploit the fact that the trace $T$ and the determinant $D$ of $J$ are the sum and the product of the eigenvalues, respectively. As stressed by Grandmont, Pintus and de Vilder (1998), the stability properties of the system, that is, the location of the eigenvalues with respect to the unit circle, can be quite easily characterized in the $(T, D)$-plane.

More explicitly, we evaluate the characteristic polynomial $P(X) \equiv X^{2}-$ $T X+D$ at $-1,0$ and 1 (see Figures 1-3). Along the line $(A C)$, one eigenvalue is equal to 1 , i.e. $P(1)=1-T+D=0$. Along the line $(A B)$, one eigenvalue is equal to -1 , i.e. $P(-1)=1+T+D=0$. On the segment $[B C]$, the two eigenvalues are complex and conjugate with unit modulus, i.e. $D=1$ and $|T|<2$. Therefore, inside the triangle $A B C$, the steady state is a sink, i.e. locally indeterminate $(D<1$ and $|T|<1+D)$. It is a saddle point if $(T, D)$ lies on the right sides of both $(A B)$ and $(A C)$ or on the left sides of both of them $(|1+D|<|T|)$. It is a source otherwise. A (local) bifurcation arises when at least one eigenvalue crosses the unit circle, that is, when the pair $(T, D)$ crosses one of the loci $(A B),(A C)$ or $[B C] .(T, D)$ depends on the structural parameters. We choose to vary a parameter of interest and observe how $(T, D)$ moves in the $(T, D)$-plane. More precisely, according to the changes in the bifurcation parameter, a pitchfork bifurcation (generically) occurs when $(T, D)$ goes through $(A C),{ }^{23}$ a flip bifurcation (generically) arises when $(T, D)$ crosses $(A B)$, whereas a Hopf bifurcation (generically) happens when $(T, D)$ goes through the segment $[B C]$.

Taking into account (3), (5), (6), (13), (34) and (16), the linearization of (32)-(33) gives:

$$
\left[\begin{array}{c}
d k_{1 t+1} / k_{1} \\
d c_{1 t+1} / c_{1}
\end{array}\right]=\left[\begin{array}{cc}
M_{1} & M_{2} \\
1 & 0
\end{array}\right]^{-1}\left[\begin{array}{cc}
0 & 1 \\
M_{3} & M_{4}
\end{array}\right]\left[\begin{array}{l}
d k_{1 t} / k_{1} \\
d c_{1 t} / c_{1}
\end{array}\right]
$$

where

$$
\begin{aligned}
M_{1} & \equiv \gamma \beta\left[B(\sigma)\left(1+\rho_{21}\right)-\rho_{21}\right] \sigma_{11} \\
M_{2} & \equiv 1+\gamma \beta B(\sigma)\left(1+\rho_{21}\right) \frac{\lambda_{1} \varepsilon_{1}}{1+\omega_{21}} \\
M_{3} & \equiv \frac{1}{\beta}-\gamma B(\sigma)\left[1-h \lambda_{1}\left(1+\varepsilon_{1}\right)\right] \\
M_{4} & \equiv-\frac{Z}{\beta \sigma_{11}}-B(\sigma)\left[1-h \lambda_{1}\left(1+\varepsilon_{1}\right)\right] \frac{\gamma}{\sigma_{11}} \frac{\lambda_{1} \varepsilon_{1}}{1+\omega_{21}}
\end{aligned}
$$

\footnotetext{
${ }^{23} \mathrm{~A}$ pitchfork bifurcation (instead of a saddle or a transcritical bifurcation) generically arises because the number of steady states is generically odd.
} 
with

$$
\begin{aligned}
B(\sigma) & \equiv(1-s) /(\sigma+s \varepsilon) \\
h & \equiv g_{l}^{\prime}\left(w l_{1}\right) / g_{k}^{\prime}\left(r k_{1}\right)=g_{l}^{\prime}\left(w l_{1}\right) r / \gamma>0 \\
Z & \equiv \beta\left[\gamma h \lambda_{1} \frac{1-s}{s}\left(\frac{\varepsilon_{1}}{1+\omega_{21}}+\frac{\sigma_{11}}{\omega_{11}}\right)+\sigma_{11}\left(\frac{\gamma}{\rho_{11}}-\delta\right)\right]>0
\end{aligned}
$$

and $\gamma \equiv 1 / \beta-1+\delta$.

Therefore, the determinant and trace are respectively given by:

$$
\begin{aligned}
& D(\sigma)=M_{3} / M_{2} \\
& T(\sigma)=M_{3}+\left(1-M_{1} M_{4}\right) / M_{2}
\end{aligned}
$$

Despite of these complicate expressions, two simple features arise.

(1) The locus $\Sigma \equiv\{(T(\sigma), D(\sigma)): \sigma \geq 0\}$ obtained by varying the capitallabor substitution in the $(T, D)$-plane is linear and allows us to apply the geometrical method introduced by Grandmont, Pintus and de Vilder (1998). ${ }^{24}$ The slope of $\Sigma$ is given by:

$$
\begin{aligned}
S & =\frac{D^{\prime}(\sigma)}{T^{\prime}(\sigma)} \\
& =\frac{1-h \lambda_{1}\left(1+\varepsilon_{1}\right)+\left(1+\rho_{21}\right) \frac{\lambda_{1} \varepsilon_{1}}{1+\omega_{21}}}{\left[1-h \lambda_{1}\left(1+\varepsilon_{1}\right)-\left(1+\rho_{21}\right) Z\right]\left(1+\rho_{21} \gamma \beta \frac{\lambda_{1} \varepsilon_{1}}{1+\omega_{21}}\right)+\left(1+\rho_{21}\right) \beta \frac{\lambda_{1} \varepsilon_{1}}{1+\omega_{21}}}
\end{aligned}
$$

(2) The endpoint of $\Sigma$ is $(T(+\infty), D(+\infty))=\left(1+1 / \beta-\gamma \rho_{21} Z, 1 / \beta\right)$.

A first important result we obtain in line with Becker and Foias (1987, 1994) and Bosi and Seegmuller (2007) is that a sufficiently high capital-labor substitution rules out the occurrence of fluctuations. More precisely, without introducing additional restrictions on the tax rules, we can prove that, under an elasticity of capital-labor substitution high enough, not only there is no longer room for two-period cycles, but also indeterminacy is ruled out, whatever the degree of marginal progressivity in taxation. Formally:

Proposition 14 There exists $\sigma^{*}$ such that $\sigma>\sigma^{*}$ implies saddle-path stability.

Proof. See the Appendix.

\subsection{Local dynamics when capitalists supply no labor}

A nice outcome of heterogeneous discounting is a micro-founded endogenous segmentation in social classes (capitalists and workers): only patient agents hold

\footnotetext{
${ }^{24}$ Becker and Foias (1994) choose the same parameter to make the bifurcation analysis, while following a different (non-geometrical) approach.
} 
capital and only impatient ones supply labor $\left(k_{2}=l_{1}=0\right)$. This important case deserves a deepening of the stability properties.

Since $\lambda_{1}=0$, the average elasticity of labor supply reduces to the elasticity of impatient agents, i.e. $\varepsilon=\varepsilon_{2}$, and marginal progressivity can play a role on the dynamics only through two parameters, $\left|\rho_{21}\right|$ and $\left|\omega_{22}\right|$. Therefore, the determinant and trace (41)-(42) simplify to: $:^{25}$

$$
\begin{aligned}
D(\sigma) & =\frac{1}{\beta}-\gamma \frac{1-s}{\sigma+s \varepsilon} \\
T(\sigma) & =1+\frac{1}{\beta}-\gamma \frac{1-s}{\sigma+s \varepsilon} \frac{1}{S}-\gamma \rho_{21} Z
\end{aligned}
$$

where now $Z=\beta\left(\gamma / \rho_{11}-\delta\right) \sigma_{11}>0$ and the slope of the $\Sigma$-line becomes:

$$
S=\frac{1}{1-\left(1+\rho_{21}\right) Z}
$$

We begin the analysis by few observations (see also Figure 1). When $\sigma$ is increasing, $(T(\sigma), D(\sigma))$ moves on the line $\Sigma$ in such a way that $D(\sigma)$ is strictly increasing. In particular, when $\sigma$ tends to $+\infty$, one reaches the following point in the $(T, D)$-plane:

$$
D(+\infty)=1 / \beta>1 \text { and } T(+\infty)=1+1 / \beta-\gamma \rho_{21} Z>1+D(+\infty)
$$

which is below the line $(A C)$ and above the horizontal axis, i.e. in the saddlepath region. In order to address the issue of the role of marginal progressivity on local dynamics, it is convenient to analyze the location of the line $\Sigma$ when $\rho_{21}$ decreases from 0 to $-\infty$, that is, when the marginal progressivity on capital taxation increases. Using (44) and (45), we can deduce that for all value of $\rho_{21}$, $\Sigma$ goes through the following fixed point $G$ :

$$
\left(T_{G}, D_{G}\right)=(2-\delta+\gamma Z, 1-\delta)
$$

which corresponds to $\sigma=1-s(1+\varepsilon) \cdot{ }^{26}$ Note that this fixed point is located below the line $(A C)$ and above the horizontal axis. Since $D_{G}<1<D(+\infty)<$ $T(+\infty)-1, \Sigma$ always goes on the right side of point $C$, which excludes any Hopf bifurcation. Now, by direct inspection of (46) and (47), we observe that, when $\rho_{21}$ decreases, the line $\Sigma$ makes a clockwise rotation around $G$. When $\rho_{21}$ tends to $0, S=1 /(1-Z)$ is strictly greater than 1 or negative. For $\rho_{21}=-1$, we have $S=1$, but $\Sigma$ still lies below point $A$. Finally, $\Sigma$ goes through $A$ for $\rho_{21}=\rho_{A},{ }^{27}$ where:

$$
\rho_{A} \equiv-\frac{1+\beta}{\beta(2-\delta)}<-1
$$

\footnotetext{
${ }^{25}$ Using (36)-(39), we get $M_{1}=\beta \gamma \sigma_{11}\left[B(\sigma)\left(1+\rho_{21}\right)-\rho_{21}\right], M_{2}=1, M_{3}=1 / \beta-\gamma B(\sigma)$ and $M_{4}=\delta-\gamma / \rho_{11}=-c_{1} / k_{1}$.

${ }^{26}$ This fixed point is obtained deriving $D(\sigma)$ and $T(\sigma)$ with respect to $\rho_{21}$.

${ }^{27}$ In this case, we have $S=1 /\left[1+Z_{\gamma} /(2-\delta)\right] \in(0,1)$.
} 
and has a slope which tends to 0 when $\rho_{21}$ tends to $-\infty$. Since $D_{G} \in(0,1), \Sigma$ goes through $A B C$ for all $\rho_{21}<\rho_{A}$. Let:

$$
\begin{aligned}
\sigma_{P} & \equiv s\left(\varepsilon_{P}-\varepsilon\right) \\
\sigma_{F} & \equiv s\left(\varepsilon_{F}-\varepsilon\right)
\end{aligned}
$$

with

$$
\begin{aligned}
\varepsilon_{P} & \equiv \frac{1-s}{s} \frac{1+\rho_{21}}{\rho_{21}} \\
\varepsilon_{F} & \equiv \frac{1-s}{s} \frac{2 \beta \gamma-\left(1+\rho_{21}\right) \beta \gamma Z}{2(1+\beta)-\rho_{21} \beta \gamma Z}
\end{aligned}
$$

solving $D\left(\sigma_{P}\right)=T\left(\sigma_{P}\right)-1$ and $D\left(\sigma_{F}\right)=-T\left(\sigma_{F}\right)-1$, respectively. For $\rho_{21}<$ $\rho_{A}$, the line $\Sigma$ crosses the line $(A B)$ for a smaller value of $\sigma$ than when it crosses $(A C)$, whereas we get the opposite conclusion $\left(\sigma_{P}<\sigma_{F}\right)$ for $\rho_{A}<\rho_{21}<0$.

Using these geometrical arguments, we deduce the following proposition:

Proposition 15 Under Assumptions 1-3 and $K_{0}>0$, a steady state characterized by $k_{1}>0, l_{2}>0$ and $k_{2}=l_{1}=0$ (see Proposition 3) has the following local stability properties.

(i) When $\rho_{A}<\rho_{21}<0$, the steady state is a saddle for $0<\sigma<\sigma_{P}$, a source for $\sigma_{P}<\sigma<\sigma_{F}$, and a saddle for $\sigma_{F}<\sigma$.

(ii) When $\rho_{21}<\rho_{A}$, the steady state is a saddle for $0<\sigma<\sigma_{F}$, a sink (indeterminate) for $\sigma_{F}<\sigma<\sigma_{P}$, and a saddle for $\sigma_{P}<\sigma$.

A flip bifurcation generically occurs at $\sigma=\sigma_{F}$ and a pitchfork bifurcation at $\sigma=\sigma_{P}$.

In accordance with Proposition 14, saddle-path stability is ensured by a sufficiently high capital-labor substitution $\left(\sigma>\max \left\{\sigma_{F}, \sigma_{P}\right\}\right)$.

We further note that some configurations obtained in this proposition also depend on the location of the starting point $(T(0), D(0))$ on the line $\Sigma$, which is measured by the level of $\varepsilon=\varepsilon_{2}$ with respect to $\varepsilon_{P}$ and $\varepsilon_{F}$. For instance, if $\varepsilon>\varepsilon_{F}$, a flip bifurcation never emerges because $\sigma_{F}<0<\sigma$. In a similar way, if $\varepsilon>\varepsilon_{P}$, a pitchfork bifurcation never emerges because $\sigma_{P}<0<\sigma$.

Case (i) of the proposition states that when $\rho_{A}<\rho_{21}<0$ and $\varepsilon<\varepsilon_{F}$, a flip bifurcation can occur. Therefore, even if the marginal progressivity of the capital tax rate is not too large, endogenous cycles can occur. This does not only require a not too large value of the capital-labor substitution, but also a sufficiently weak value for $\varepsilon_{2} \cdot{ }^{28}$ When the marginal progressivity of the capital tax rate is sufficiently high, not only cycles of period 2 can occur (if $\varepsilon<\varepsilon_{F}$ ), but also expectation-driven fluctuations (if $\varepsilon<\varepsilon_{P}$ ).

To analyze more precisely the effect of marginal progressivity on macroeconomic (in)stability, we need the following lemma:

\footnotetext{
${ }^{28}$ See Bosi and Seegmuller (2007) for a similar result in a less general model without taxes, or Becker and Foias $(1987,1994)$ in a more specific framework with inelastic labor supply and no taxation.
} 


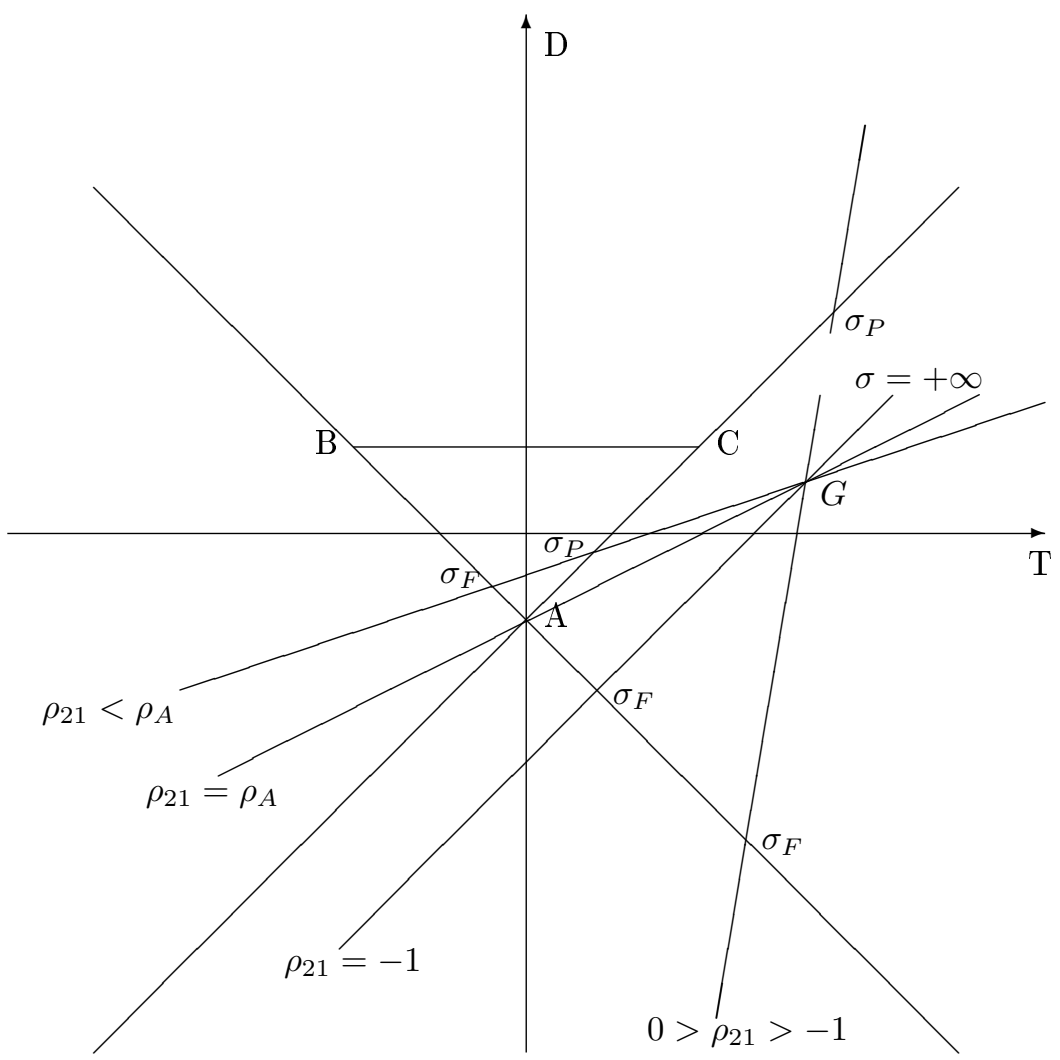

Figure 1: Capitalists supply no labor

\section{Lemma 4}

(i) $\partial \sigma_{P} / \partial\left|\omega_{22}\right|=\partial \sigma_{F} / \partial\left|\omega_{22}\right|>0$;

(ii) $\partial \sigma_{P} / \partial\left|\rho_{21}\right|>0, \partial \sigma_{F} / \partial\left|\rho_{21}\right|>0$;

(iii) $\partial\left(\sigma_{P}-\sigma_{F}\right) / \partial\left|\rho_{21}\right|>0$ iff

$$
\rho_{21}>-\frac{2(1+\beta) / \beta}{2-\delta} \text { or } \gamma Z<\frac{2(1+\beta)^{2} /\left(\beta \rho_{21}\right)^{2}}{2-\delta+2(1+\beta) /\left(\beta \rho_{21}\right)}
$$

Proof. See the Appendix.

This lemma implies two corollaries about the role of progressivity in the occurrence of deterministic and stochastic endogenous fluctuations.

Corollary 3 Marginal progressivity in taxation promotes the occurrence of persistent cycles. 
This corollary can be explained as follows. Recall that endogenous cycles generically occur when $\sigma$ crosses the critical value $\sigma_{F}$. Then, on the one hand, if $\sigma_{F}<0$ (that is $\varepsilon>\varepsilon_{F}$ ), increasing the progressivity measures $\left|\rho_{21}\right|$ or $\left|\omega_{22}\right|$ can make the interval $\left(0, \sigma_{F}\right)$ non-empty. On the other hand, if $0<\sigma_{F}$, raising $\left|\rho_{21}\right|$ or $\left|\omega_{22}\right|$ widens $\left(0, \sigma_{F}\right)$, making cycles more likely, because they generically occur for a higher degree of capital-labor substitution.

We now analyze the role of marginal progressivity on local indeterminacy:

Corollary 4 Under $\rho_{21}<\rho_{A}$ (or, equivalently, $\varepsilon_{F}<\varepsilon_{P}$ ) and the assumption of Lemma 4, marginal progressivity in taxation promotes indeterminacy.

To explain this corollary, assume first that $\sigma_{F}<0$ (that is $\varepsilon>\varepsilon_{F}$ ) and recall that indeterminacy occurs for $\sigma$ that belongs to $\left(\sigma_{F}, \sigma_{P}\right)$. On the one hand, a larger marginal progressivity, measured by $\left|\rho_{21}\right|$ or $\left|\omega_{22}\right|$, can either make the interval $\left(0, \sigma_{P}\right)$ nonempty, or widen it. On the other hand, under the assumptions of Lemma 4 , when $\sigma_{F}>0$ (that is $\varepsilon<\varepsilon_{F}$ ), the extent of the indeterminacy range $\left(\sigma_{P}-\sigma_{F}\right)$ is invariant w.r.t. the marginal progressivity on labor, but widens with the marginal progressivity on capital.

Hence, this section shows that in contrast to several existing results, progressive tax rules do not play a stabilizing role, but rather promote endogenous cycles and expectation-driven fluctuations. Especially, we have seen that marginal progressivity in capital taxation plays a key role on the occurrence of indeterminacy.

Still considering the case where the capital stock is held by the most patient households, we aim at analyzing further the role of progressivity in labor income taxation.

To this purpose, we introduce a flat tax on capital income, but we generalize the analysis to the case where both the types of agents supply a positive amount of labor. In such a framework, we will be able to study the role on dynamics of labor tax rates that also affect the most patient agents' wage earnings.

\subsection{Local dynamics under a flat tax on capital income}

Assuming a flat tax on capital income, we have $\tau_{k}\left(r_{t} k_{1 t}\right)=r_{t} k_{1 t}-g_{k}\left(r_{t} k_{1 t}\right) \equiv$ $t_{k} r_{t} k_{1 t}+T_{k}$, with $t_{k} \in[0,1)$. Therefore, we have $g_{k}\left(r_{t} k_{1 t}\right) \equiv\left(1-t_{k}\right) r_{t} k_{1 t}-T_{k}$ and $\rho_{21}=0 .{ }^{29}$ Focusing on dynamics in a neighborhood of a steady state with $k_{1}>0, l_{1}>0, l_{2}>0$ and $k_{2}=0$, and using equations (41)-(43), the trace $T(\sigma)$, the determinant $D(\sigma)$ and the slope $S$ simplify to:

$$
\begin{aligned}
T(\sigma) & =\frac{1}{\beta}+\frac{1+\gamma B(\sigma) Z-\gamma B(\sigma)\left[1-h \lambda_{1}\left(1+\varepsilon_{1}\right)\right]}{1+\gamma \beta B(\sigma) \frac{\lambda_{1} \varepsilon_{1}}{1+\omega_{21}}} \\
D(\sigma) & =T(\sigma)-1-\left[Z+(1-\beta) \frac{\lambda_{1} \varepsilon_{1}}{1+\omega_{21}}\right] \frac{\gamma B(\sigma)}{1+\gamma \beta B(\sigma) \frac{\lambda_{1} \varepsilon_{1}}{1+\omega_{21}}} \\
S & =\frac{H}{H-Z-(1-\beta) \frac{\lambda_{1} \varepsilon_{1}}{1+\omega_{21}}}
\end{aligned}
$$

${ }^{29}$ Note that, when $T_{k}=0$, we further have $\rho_{11}=1$. 
with $H \equiv 1-h \lambda_{1}\left(1+\varepsilon_{1}\right)+\lambda_{1} \varepsilon_{1} /\left(1+\omega_{21}\right)$.

We start the analysis by noting that when $\sigma$ tends to $+\infty$, the line $\Sigma$ crosses $(A C)$ above $C$. Indeed, we have $D(+\infty)=1 / \beta>1$ and $T(+\infty)=1+1 / \beta=$ $1+D(+\infty)$. Therefore, a pitchfork bifurcation can never occur. In accordance with Corollary 1 , the steady state is unique when $\rho_{21}=0$.

By direct inspection of (56), we further notice that two main configurations may emerge, depending on the sign of $H$ :

(i) if $H>0$, we have $S>1$ or $S<0$ and $D^{\prime}(\sigma)>0$;

(ii) if $H<0$, we have $0<S<1$ and $D^{\prime}(\sigma)<0$.

Let $h^{*} \equiv\left(1+l_{1} /\left[\left(1-l_{1}\right) \sigma_{21}\right]\right)^{-1} \in(0,1)$. Using (34), the inequality $H<0$ can be rewritten $\omega_{21}>\underline{\omega}_{21}$, with $\underline{\omega}_{21} \equiv(\underline{h}-h) \lambda_{1} / h^{*}$ and $\underline{h} \equiv\left[1-\left(1-\lambda_{1}\right) h^{*}\right] / \lambda_{1}>$ 1.

Therefore, configuration (i) applies iff $0<h<\underline{h}$ or $\omega_{21}<\underline{\omega}_{21}$, whereas configuration (ii) holds iff $h>\underline{h}$ and $\underline{\omega}_{21}<\omega_{21}<0$.

Focus first on configuration (i) (see also Figure 2). ${ }^{30}$ Since $(T(+\infty), D(+\infty))$ is on the line $(A C)$ above $C, D(\sigma)$ is strictly increasing and the slope $S$ does not belong to $(0,1)$, we geometrically see that $\Sigma$ can never goes through $A B C$ and can only crosses the line $(A B){ }^{31}$ Let us define $\sigma_{F} \equiv s\left(\varepsilon_{F}-\varepsilon\right)$, with:

$$
\varepsilon_{F} \equiv \beta \gamma \frac{1-s}{s}\left[\frac{1-h \lambda_{1}\left(1+\varepsilon_{1}\right)-Z / 2}{1+\beta}-\frac{1}{2} \frac{\lambda_{1} \varepsilon_{1}}{1+\omega_{21}}\right]
$$

that solves $D(\sigma)=-T(\sigma)-1$. By continuity, $(T(\sigma), D(\sigma))$ is always in the saddle region for $\sigma>\sigma_{F}$, whereas the steady state is a source for $\sigma<\sigma_{F}$. We observe that this last case also requires $\varepsilon<\varepsilon_{F}$, because otherwise $\sigma_{F}<0$.

Consider now configuration (ii) (see also Figure 3 ). Since $(T(+\infty), D(+\infty))$ is on the line $(A C)$ above $C, D(\sigma)$ is strictly decreasing and the slope $S$ belongs to $(0,1), \Sigma$ can go through the triangle $A B C$. To clearly identify the conditions such that this really occurs, we need the following lemma:

Lemma 5 For $h>\underline{h}$, the slope $S$ is strictly increasing in $\omega_{21}$.

Proof. See the Appendix.

Therefore, for $h>\underline{h}$, the line $\Sigma$ makes a clockwise rotation around the fixed point $(T(+\infty), D(+\infty))$ when $\omega_{21}$ decreases from 0 to $\underline{\omega}_{21}$, i.e. the slope $S$ decreases from a value between 0 and 1 to 0 in the limit case where $\omega_{21}=\underline{\omega}_{21}$. In the following, we define $\omega_{21}^{*}$ as the critical value of $\omega_{21}$ such that the line $\Sigma$ goes through the point $B$ :

$$
\omega_{21}^{*} \equiv \frac{1-h^{*}}{h^{*}}-\frac{\lambda_{1}}{h^{*}} \frac{h\left[4-(1-\beta) h^{*} \gamma \frac{1-s}{s}\right]-h^{*} \frac{(1+\beta)^{2}}{\beta}}{4+\sigma_{11}(1-\beta)\left(\frac{\gamma}{\rho_{11}}-\delta+\lambda_{1} h \frac{\gamma}{\omega_{11}} \frac{1-s}{s}\right)}
$$

\footnotetext{
${ }^{30}$ Note that Figure 2 is drawn for $S<-1$, but figures representing similar qualitative results should be done for $S>1$ and $-1<S<0$.

${ }^{31}$ The locus $\Sigma$ crosses $(A B)$ below $A$ if $|S|>1$ or above $B$ if $-1<S<0$. See also Bosi and Seegmuller (2007) who obtain similar geometrical representations in a model without taxation.
} 
Clearly, when $\omega_{21}^{*} \geq 0, \Sigma$ lies above $B$ for all $\omega_{21} \in\left(\underline{\omega}_{21}, 0\right)$, while when $\omega_{21}^{*}<0, \Sigma$ lies above $B$ for $\omega_{21} \in\left(\underline{\omega}_{21}, \omega_{21}^{*}\right)$ and below $B$ for $\omega_{21} \in\left(\omega_{21}^{*}, 0\right)$. In this last case, the critical value $\sigma_{H} \equiv s\left(\varepsilon_{H}-\varepsilon\right)$, defined by $D(\sigma)=1$, with

$$
\varepsilon_{H} \equiv \beta \gamma \frac{1-s}{s}\left[\frac{1-h \lambda_{1}\left(1+\varepsilon_{1}\right)}{1-\beta}+\frac{\beta}{1-\beta} \frac{\lambda_{1} \varepsilon_{1}}{1+\omega_{21}}\right]
$$

corresponds to the lower bound of $\sigma$ for indeterminacy to occur. ${ }^{32}$ Using all these geometrical arguments, we deduce the next proposition:

Proposition 16 Under Assumptions 1-3 and $K_{0}>0$, a steady state characterized by $k_{1}>0, l_{1}>0, l_{2}>0$ and $k_{2}=0$ (see Proposition 3) has the following local stability properties.

(i) When $0<h<\underline{h}$ or $\left(h>\underline{h}\right.$ and $\left.\omega_{21}<\omega_{21}^{*}\right)$, the steady state is a source for $0<\sigma<\sigma_{F}$ and a saddle for $\sigma_{F}<\sigma$.

(ii) When $h>\underline{h}$ and $\omega_{21}^{*}<\omega_{21}<0$, the steady state is a source for $0<\sigma<\sigma_{H}$, a sink (indeterminate) for $\sigma_{H}<\sigma<\sigma_{F}$, and a saddle for $\sigma>\sigma_{F}$.

A flip bifurcation generically occurs at $\sigma=\sigma_{F}$ and a Hopf bifurcation at $\sigma=\sigma_{H}$.

This proposition shows that if $\varepsilon<\varepsilon_{F}$, endogenous cycles of period 2 can emerge. Recalling $\varepsilon=\lambda_{1} \varepsilon_{1}+\lambda_{2} \varepsilon_{2}$, this requires a sufficiently small value of $\varepsilon_{2}$, ensured for instance by a sufficiently weak elasticity of intertemporal substitution in consumption $\sigma_{12}$. Note that the occurrence of a Hopf bifurcation requires even a smaller elasticity $\varepsilon_{2} \cdot{ }^{33}$ Surprisingly, indeterminacy emerges only if marginal progressivity on labor income of patient households is not too large $\left(\omega_{21}>\omega_{21}^{*}\right)$. However, it also requires $h>\underline{h}$, i.e., using $h=$ $\left[1-\tau_{l}^{\prime}\left(\omega l_{1}\right)\right] /\left(1-t_{k}\right)$ (see (40)), a sufficiently large distortionary tax rate on capital income $t_{k}>1-\left[1-\tau_{l}^{\prime}\left(w l_{1}\right)\right] / \underline{h}$. In other words, expectations-driven fluctuations appear if the net income of patient consumers $g_{l}\left(w l_{1}\right)+g_{k}\left(r k_{1}\right)$ depends little on capital income. It is also interesting to notice that in configuration (ii) of the proposition, because we have $H<0$, we can deduce that $\varepsilon_{F}<0$. Therefore, if the average elasticity of labor supply $\varepsilon$ is positive, we obtain $\sigma_{F}<0$, that is, the steady state is a saddle for all $\sigma>0$.

Now, to further investigate the role of progressivity on macroeconomic (in)stability, the following results are needed:

\section{Lemma 6}

(i) $\partial \sigma_{H} / \partial\left|\omega_{22}\right|=\partial \sigma_{F} / \partial\left|\omega_{22}\right|>0$.

(ii) $\partial \sigma_{F} / \partial\left|\omega_{21}\right|>0$.

\footnotetext{
${ }^{32} \mathrm{By}$ direct inspection of the expression of $\sigma_{H}$, we see that it is strictly positive if and only if $\varepsilon<\varepsilon_{H}$.

${ }^{33}$ Indeed, in configuration (ii) of Proposition 16, we have $\varepsilon_{H}<\varepsilon_{F}$.
} 


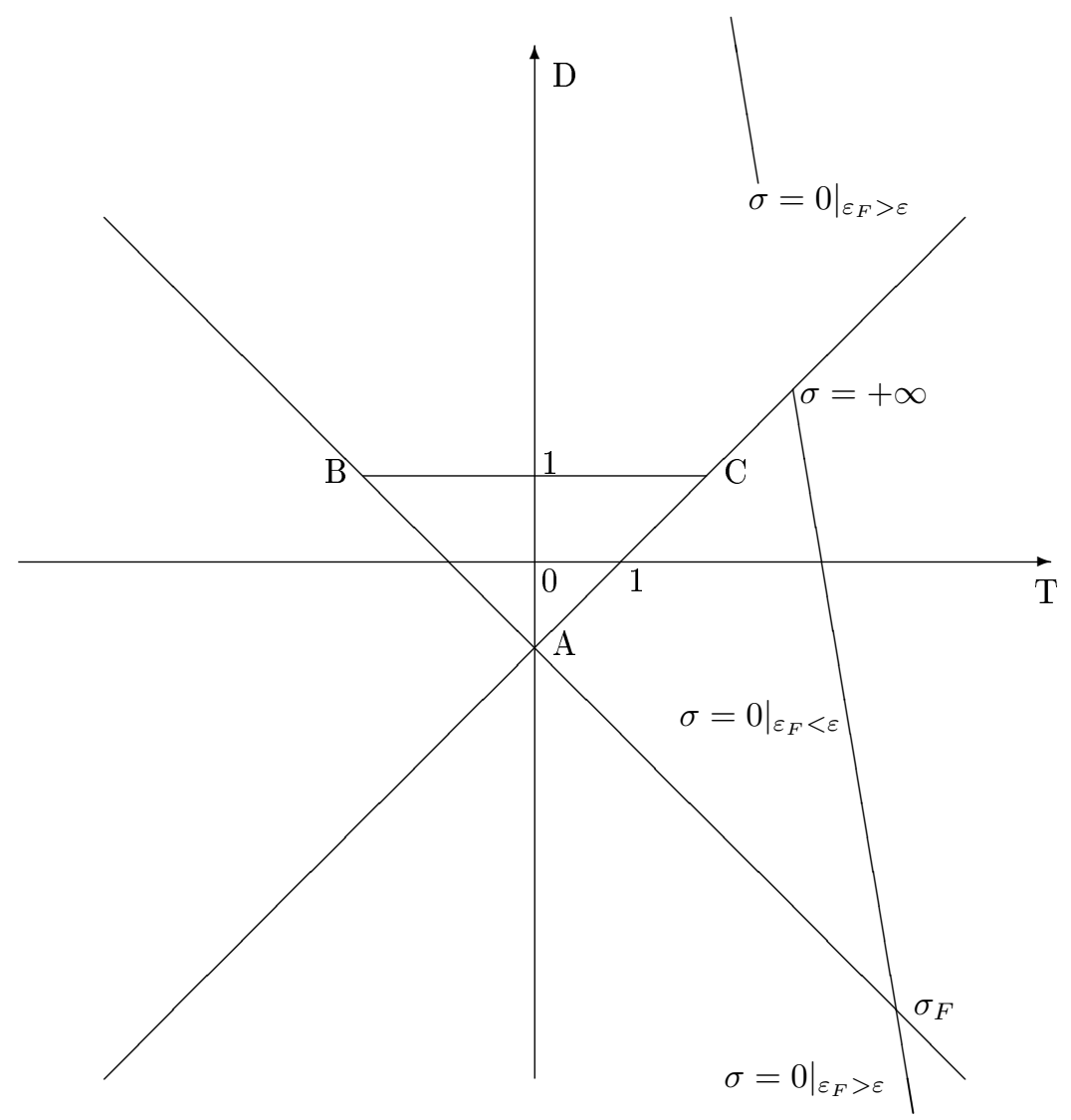

Figure 2: Flat tax on capital income with $S<-1$

(iii) $h>\underline{h}$ implies $\partial \sigma_{H} / \partial\left|\omega_{21}\right|>0$.

(iv) $\omega_{21}^{*}<0$ implies $\partial\left(\sigma_{F}-\sigma_{H}\right) / \partial\left|\omega_{21}\right|<0$.

Proof. See the Appendix.

Using this lemma, we are now able to study how progressivity affects the occurrence of endogenous cycles and local indeterminacy.

Corollary 5 Progressivity in labor income taxation promotes the occurrence of persistent cycles.

According to Lemma 6, a higher marginal progressivity, through an increase of $\left|\omega_{21}\right|$ or $\left|\omega_{22}\right|$ raises the two critical values $\sigma_{F}$ and $\sigma_{H}$. In case (i) of Proposition 16 , both the progressivities $\left|\omega_{21}\right|$ and $\left|\omega_{22}\right|$ either make $\sigma_{F}$ positive and nonempty the interval $\left(0, \sigma_{F}\right)$ where two-period cycles arise, or enlarge the interval $\left(0, \sigma_{F}\right)$. In case (ii) of Proposition 16 , the range $\left(0, \sigma_{H}\right)$ for limit cycles also widens. 


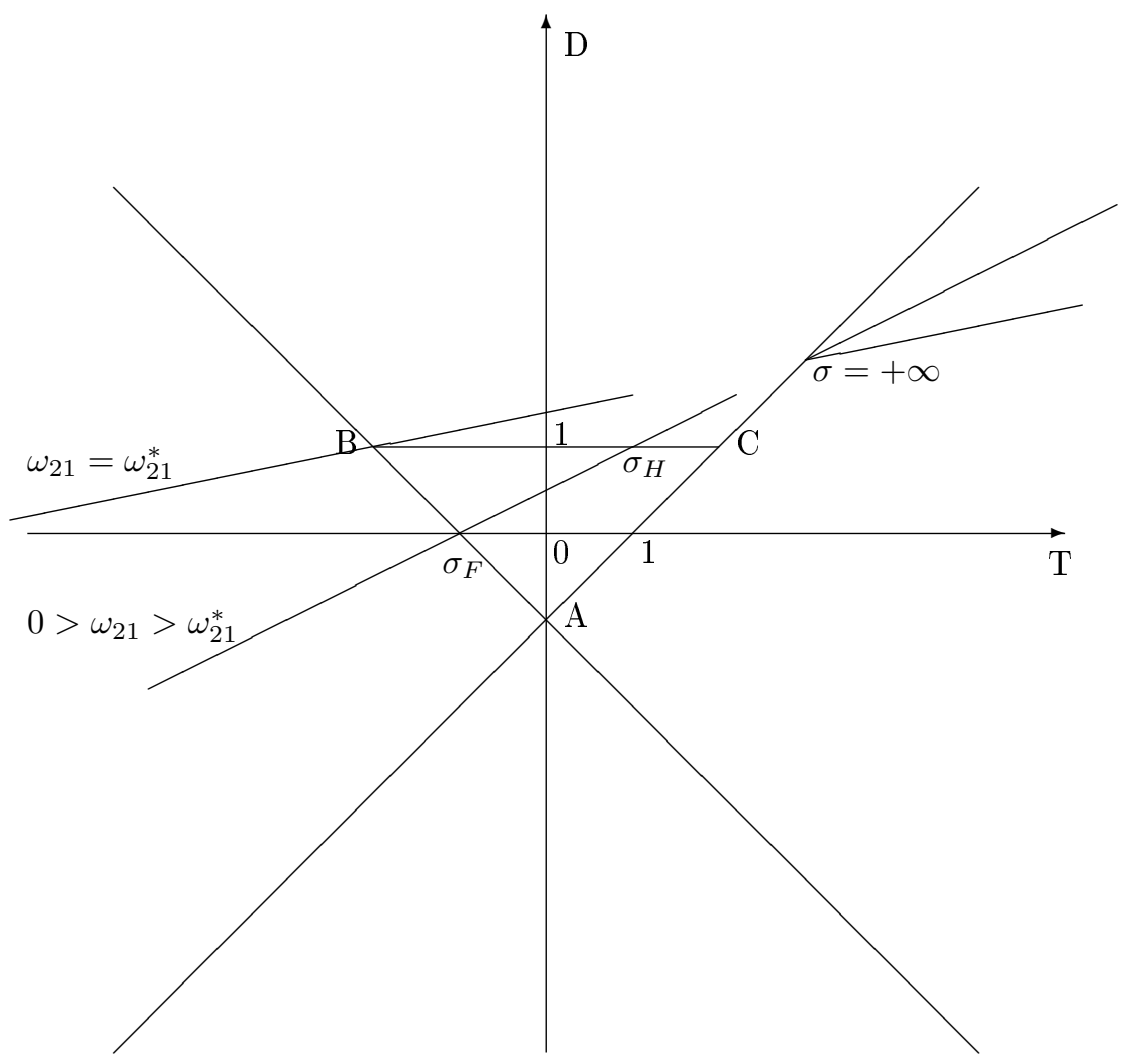

Figure 3: Flat tax on capital income with $0<S<1$

Corollary 6 Assume $h>\underline{h}$ and $\omega_{21}^{*}<\omega_{21}<0$.

(i) When $\varepsilon>\varepsilon_{H}$, increasing progressivity in the labor tax rules promotes indeterminacy.

(ii) When $\varepsilon \leq \varepsilon_{H}$, increasing progressivity for patient households promotes determinacy, whereas indeterminacy occurs for higher elasticities of capitallabor substitution under a higher progressivity for impatient households.

To explain this corollary, consider first case (i) where $\sigma_{H}<0$. Progressivity promotes indeterminacy because, according to points (i) and (ii) of Lemma 6, an increase of $\left|\omega_{21}\right|$ or $\left|\omega_{22}\right|$ either makes the indeterminacy range $\left(0, \sigma_{F}\right)$ nonempty or enlarges it. In case (ii) of Corollary 6 , the result comes from the fact that, according to point (iv) of Lemma 6 , an increase of $\left|\omega_{21}\right|$ reduces the amplitude of the indeterminacy interval $\left(\sigma_{H}, \sigma_{F}\right)^{34}$ and, according to point (i) of Lemma 6 ,

\footnotetext{
${ }^{34}$ This should also be seen using geometrical arguments. Indeed, we have $0<S<1$ and $\Sigma$ makes a clockwise rotation around $(T(\infty), D(\infty))$ when $\left|\omega_{21}\right|$ increases from 0 . In particular, when $\left|\omega_{21}\right|$ tends to $\left|\omega_{21}^{*}\right|, \Sigma$ reaches the point $B$ and $\sigma_{H}$ converges to $\sigma_{F}$.
} 
an increase of $\left|\omega_{22}\right|$ raises both $\sigma_{H}$ and $\sigma_{F}$, while keeping the difference $\sigma_{F}-\sigma_{H}$ as constant.

\subsection{Interpretation}

To give an economic intuition for the occurrence of endogenous cycles and expectation-driven fluctuations, recall that the dynamics are governed by the two following equations:

$$
\begin{aligned}
c_{1 t}+k_{1 t+1}-(1-\delta) k_{1 t} & =I_{k t}+I_{l t} \\
u_{1}^{\prime}\left(c_{1 t}\right) & =\beta R_{t+1} u_{1}^{\prime}\left(c_{1 t+1}\right)
\end{aligned}
$$

where on the one hand, $I_{k t} \equiv g_{k}\left(r_{t} k_{1 t}\right)$ and $I_{l t} \equiv g_{l}\left(w_{t} l_{1 t}\right)$ are the capitalists' after-tax capital and labor incomes, respectively, and on the other hand, $R_{t+1} \equiv$ $1-\delta+g_{k}^{\prime}\left(r_{t+1} k_{1 t+1}\right) r_{t+1}$ represents the after-tax real interest factor.

We start by focusing on the case where capitalists supply no labor, i.e. $I_{l t}=0$. We have shown that when the marginal progressivity on capital income is not too large $\left(\rho_{21}>\rho_{A}\right)$, cycles of period 2 may emerge (see Proposition 15). To provide an intuition for this phenomena, related to Becker and Foias (1987, 1994) and Bosi and Seegmuller (2007), we note that: ${ }^{35}$

$$
\frac{\partial I_{k t}}{\partial k_{1 t}} \frac{k_{1 t}}{I_{k t}}=\rho_{11} \frac{\sigma-[1-s(1+\varepsilon)]}{\sigma+s \varepsilon}<0 \text { iff }-s \varepsilon<\sigma<1-s(1+\varepsilon)
$$

In this case, when $k_{1 t}$ decreases w.r.t. its steady state value, $I_{k t}$ increases. According to the budget constraint (58), this entails that $k_{1 t+1}$ goes up as well, provided that $c_{1 t}$ is not subject to strong intertemporal arbitrages. More precisely, when the marginal progressivity on capital income is not too large, $c_{1 t}$ is little sensitive if the intertemporal substitution in consumption $\sigma_{11}$ is sufficiently weak. ${ }^{36}$ Then, $k_{1 t}$ successively moves down and up through time, i.e. non-monotonic trajectories and endogenous cycles occur.

By direct inspection of inequality (60), we see that a lower value of $\varepsilon$ promotes oscillations, the interval of $\sigma$ becoming compatible with positive and larger values of the capital-labor substitution. In particular, since $\varepsilon=\varepsilon_{2}$ and $\partial \varepsilon_{2} / \partial \omega_{22}>0$, this happens when the marginal progressivity on labor income $\left|\omega_{22}\right|$ is higher.

When the marginal progressivity on capital income is sufficiently large $\left(\rho_{21}<\right.$ $\left.\rho_{A}<-1\right)$, there is room for indeterminacy and expectations-driven fluctuations.

First, observe that, if $\rho_{21}<-1$,

$$
\frac{\partial R_{t+1}}{\partial k_{1 t+1}} \frac{k_{1 t+1}}{R_{t+1}}=\beta \gamma\left|\rho_{21}\right| \frac{\sigma_{P}-\sigma}{\sigma+s \varepsilon}>0 \text { iff }-s \varepsilon<\sigma<\sigma_{P}
$$

\footnotetext{
${ }^{35}$ Note that $\sigma=-s \varepsilon$ corresponds to the case where the trace $T(\sigma)$ and the determinant $D(\sigma)$ cross both $\pm \infty$.

${ }^{36}$ Indeed, we notice that, if $\sigma_{11}$ tends to $+\infty$, according to equation (53), $\varepsilon_{F}$ tends to $(1-s)\left(1+\rho_{21}\right) /\left(s \rho_{21}\right)$ and $\sigma_{F}$ is no longer positive when $\left|\rho_{21}\right|$ becomes sufficiently weak.
} 
Then, optimistic expectations on the future real interest factor $R_{t+1}$ are compatible with higher investment, higher future consumption $c_{1 t+1}$ and/or a smaller current consumption $c_{1 t}$, and support the oscillations explained above.

Consider now that all agents have a positive labor supply, but there is a flat tax on capital income. Hence, to simplify, we assume that $I_{k t}=\left(1-t_{k}\right) r_{t} k_{1 t}$, which implies that $\rho_{11}=1$ and $\rho_{21}=0$. When $h<\underline{h},{ }^{37}$ the effect of $I_{k t}$ on the budget constraint (58) is greater than that of $I_{l t}$. In such a case, the channel of inequality $(60)$ works (with $\rho_{11}=1$ ) and there is room for cycles of period 2 , as explained above. In addition, an increase of either $\left|\omega_{21}\right|$ or $\left|\omega_{22}\right|$ promotes cycles, reducing $\varepsilon=\lambda_{1} \varepsilon_{1}+\lambda_{2} \varepsilon_{2}$.

When $h>\underline{h}$, the impact of the labor income $I_{l t}$ on the budget constraint (58) prevails w.r.t. that of $I_{k t}$. We further have:

$$
\frac{\partial I_{l t}}{\partial k_{1 t}} \frac{k_{1 t}}{I_{l t}}=\omega_{11}\left(1+\varepsilon_{1}\right) \frac{s}{\sigma+s \varepsilon}<0 \text { iff } \sigma<-s \varepsilon
$$

When condition (62) holds, following a negative deviation of $k_{1 t}$ from its steady state value, $I_{l t}$ raises and $k_{1 t+1}$ moves also up, provided that consumption is little sensitive. The condition $\sigma<-s \varepsilon$ being in accordance with the findings of Proposition 16 (ii), ${ }^{38}$ this explains the emergence of oscillations. Since indeterminacy can occur, fluctuations should be driven by expectations. To explain this phenomena, note that:

$$
\frac{\partial R_{t+1}}{\partial k_{1 t+1}} \frac{k_{1 t+1}}{R_{t+1}}=-\beta \gamma \frac{1-s}{\sigma+s \varepsilon}>0 \text { iff } \sigma<-s \varepsilon
$$

Therefore, from equation (59), optimistic expectations on the future real interest factor are sustained by a higher investment, a smaller current consumption and/or a higher future consumption, ${ }^{39}$ that are in accordance with the occurrence of the non-monotonic trajectories explained above.

\section{Concluding remarks}

In this paper, we analyze the effects of progressive taxation on the allocations of steady state and the local dynamics in a Ramsey economy with heterogeneous households and borrowing constraints. Because labor supply is endogenous, considering different taxes on labor and capital income matters.

For simplicity, we have considered a population of only two kinds of agents. We show that, at a steady state, the level of real interest rate determines whether only patient consumers hold capital or both types of agents have positive savings. Moreover, it is not always optimal for any households to supply labor.

\footnotetext{
${ }^{37}$ This is ensured by $t_{k}$ sufficiently small and $\tau_{l}^{\prime}\left(w_{t} l_{1 t}\right)$ high enough.

${ }^{38}$ Indeed, we have $\sigma_{H}<\sigma_{F}<-s \varepsilon$.

${ }^{39}$ Note that when $\sigma<-s \varepsilon$, an increase of $c_{1 t+1}$ raises $R_{t+1}$, but this effect can be considered as negligible with regard to its negative impact on $u_{1}^{\prime}\left(c_{1 t+1}\right)$.
} 
Focusing on the steady state where only patient households save through capital and only impatient supply labor, we characterize the effects of the population sizes of both types of households and the effects of the tax rates on aggregate variables (capital, production), as well as on individual incomes and welfare. We show that not only progressivity, but also endogenous labor crucially matters.

Dynamics are studied through a local analysis, in a neighborhood of the steady state where patient consumers hold all the capital stock. We show that in most of the cases, increasing marginal progressivity promotes the existence of endogenous cycles and indeterminacy, i.e. expectations-driven fluctuations. This result is in contrast to most of the existing contributions on one-sector economies and is mainly explained by the existence of a market incompleteness, due to the borrowing constraints. In any case, this paper shows that policy makers have to handle carefully the progressivity leverage to avoid macroeconomic instability.

\section{Appendix}

\section{Proof of Proposition 1}

Necessity. Conditions (P1), (P6) and (P7) directly come from the definition of an equilibrium. (P2) corresponds to the first order condition of profit maximization of the representative firm. (P3) and (P4) are the first order conditions of the utility maximization of an household $i$, while (P5) represents his budget constraint. Finally, (P8) is the balanced budget rule.

Sufficiency. To establish (D1), note first that the strict positivity of prices $\left(r_{t}, w_{t}\right)_{t=0}^{\infty}$ is ensured by (P2) and Assumption 3. Second, for every alternative pair $\left(\tilde{K}_{t}, \tilde{L}_{t}\right) \neq\left(K_{t}, L_{t}\right)$, we have:

$$
\begin{aligned}
& F\left(K_{t}, L_{t}\right)-w_{t} L_{t}-r_{t} K_{t}-\left[F\left(\tilde{K}_{t}, \tilde{L}_{t}\right)-w_{t} \tilde{L}_{t}-r_{t} \tilde{K}_{t}\right] \\
= & F\left(K_{t}, L_{t}\right)-F\left(\tilde{K}_{t}, \tilde{L}_{t}\right)-r_{t}\left(K_{t}-\tilde{K}_{t}\right)-w_{t}\left(L_{t}-\tilde{L}_{t}\right) \\
\geq & F_{k}\left(K_{t}, L_{t}\right)\left(K_{t}-\tilde{K}_{t}\right)+F_{l}\left(K_{t}, L_{t}\right)\left(L_{t}-\tilde{L}_{t}\right)-r_{t}\left(K_{t}-\tilde{K}_{t}\right)-w_{t}\left(L_{t}-\tilde{L}_{t}\right) \\
= & 0
\end{aligned}
$$

Consider now a sequence $\left(\tilde{k}_{i t}, \tilde{l}_{i t}, \tilde{c}_{i t}\right)$ satisfying the constraints in the con- 
sumer's program and the initial condition $\tilde{k}_{i 0}=k_{i 0}$. We have:

$$
\begin{aligned}
& \sum_{t=0}^{\infty} \beta_{i}^{t}\left[u_{i}\left(c_{i t}\right)+v_{i}\left(1-l_{i t}\right)\right]-\sum_{t=0}^{\infty} \beta_{i}^{t}\left[u_{i}\left(\tilde{c}_{i t}\right)+v_{i}\left(1-\tilde{l}_{i t}\right)\right] \\
& =\sum_{t=0}^{\infty} \beta_{i}^{t}\left[u_{i}\left(c_{i t}\right)-u_{i}\left(\tilde{c}_{i t}\right)+v_{i}\left(1-l_{i t}\right)-v_{i}\left(1-\tilde{l}_{i t}\right)\right] \\
& \geq \sum_{t=0}^{\infty} \beta_{i}^{t}\left[u_{i}^{\prime}\left(c_{i t}\right)\left(c_{i t}-\tilde{c}_{i t}\right)-v_{i}^{\prime}\left(1-l_{i t}\right)\left(l_{i t}-\tilde{l}_{i t}\right)\right] \\
& =\sum_{t=0}^{\infty} \beta_{i}^{t}\left(u _ { i } ^ { \prime } ( c _ { i t } ) \left[(1-\delta)\left(k_{i t}-\tilde{k}_{i t}\right)-\left(k_{i t+1}-\tilde{k}_{i t+1}\right)+g_{k}\left(r_{t} k_{i t}\right)-g_{k}\left(r_{t} \tilde{k}_{i t}\right)\right.\right. \\
& \left.\left.+g_{l}\left(w_{t} l_{i t}\right)-g_{l}\left(w_{t} \tilde{l}_{i t}\right)\right]-v_{i}^{\prime}\left(1-l_{i t}\right)\left(l_{i t}-\tilde{l}_{i t}\right)\right) \\
& \geq \sum_{t=0}^{\infty} \beta_{i}^{t}\left[u_{i}^{\prime}\left(c_{i t}\right)\left(\left[(1-\delta)+g_{k}^{\prime}\left(r_{t} k_{i t}\right) r_{t}\right]\left(k_{i t}-\tilde{k}_{i t}\right)-\left(k_{i t+1}-\tilde{k}_{i t+1}\right)\right)\right. \\
& \left.+\left[u_{i}^{\prime}\left(c_{i t}\right) g_{l}^{\prime}\left(w_{t} l_{i t}\right) w_{t}-v_{i}^{\prime}\left(1-l_{i t}\right)\right]\left(l_{i t}-\tilde{l}_{i t}\right)\right) \\
& =\lim _{T \rightarrow+\infty}\left(u_{i}^{\prime}\left(c_{i 0}\right)\left[1-\delta+g_{k}^{\prime}\left(r_{0} k_{i 0}\right) r_{0}\right]\left(k_{i 0}-\tilde{k}_{i 0}\right)\right. \\
& +\sum_{t=0}^{T-1} \beta_{i}^{t+1} u_{i}^{\prime}\left(c_{i t+1}\right)\left[1-\delta+g_{k}^{\prime}\left(r_{t+1} k_{i t+1}\right) r_{t+1}\right]\left(k_{i t+1}-\tilde{k}_{i t+1}\right) \\
& -\sum_{t=0}^{T-1} \beta_{i}^{t} u_{i}^{\prime}\left(c_{i t}\right)\left(k_{i t+1}-\tilde{k}_{i t+1}\right)-\beta_{i}^{T} u_{i}^{\prime}\left(c_{i T}\right)\left(k_{i T+1}-\tilde{k}_{i T+1}\right) \\
& \left.+\sum_{t=0}^{T} \beta_{i}^{t}\left[u_{i}^{\prime}\left(c_{i t}\right) g_{l}^{\prime}\left(w_{t} l_{i t}\right) w_{t}-v_{i}^{\prime}\left(1-l_{i t}\right)\right]\left(l_{i t}-\tilde{l}_{i t}\right)\right) \\
& =\lim _{T \rightarrow+\infty}\left(\sum_{t=0}^{T-1} \beta_{i}^{t}\left(\beta_{i} u_{i}^{\prime}\left(c_{i t+1}\right)\left[1-\delta+g_{k}^{\prime}\left(r_{t+1} k_{i t+1}\right) r_{t+1}\right]-u_{i}^{\prime}\left(c_{i t}\right)\right)\left(k_{i t+1}-\tilde{k}_{i t+1}\right)\right. \\
& -\beta_{i}^{T} u_{i}^{\prime}\left(c_{i T}\right)\left(k_{i T+1}-\tilde{k}_{i T+1}\right) \\
& \left.+\sum_{t=0}^{T} \beta_{i}^{t}\left[u_{i}^{\prime}\left(c_{i t}\right) g_{l}^{\prime}\left(w_{t} l_{i t}\right) w_{t}-v_{i}^{\prime}\left(1-l_{i t}\right)\right]\left(l_{i t}-\tilde{l}_{i t}\right)\right) \\
& \geq \lim _{T \rightarrow+\infty}\left(\sum_{t=0}^{T-1} \beta_{i}^{t}\left(\beta_{i} u_{i}^{\prime}\left(c_{i t+1}\right)\left[1-\delta+g_{k}^{\prime}\left(r_{t+1} k_{i t+1}\right) r_{t+1}\right]-u_{i}^{\prime}\left(c_{i t}\right)\right) k_{i t+1}\right. \\
& \left.-\beta_{i}^{T} u_{i}^{\prime}\left(c_{i T}\right) k_{i T+1}+\sum_{t=0}^{T} \beta_{i}^{t}\left[u_{i}^{\prime}\left(c_{i t}\right) g_{l}^{\prime}\left(w_{t} l_{i t}\right) w_{t}-v_{i}^{\prime}\left(1-l_{i t}\right)\right] l_{i t}\right)=0
\end{aligned}
$$


This proves that condition (D2) holds. (D3) is ensured by (P1), (P2) and (P8). (D4) and (D5) are obviously obtained from (P6) and (P7), while we deduce (D6) using (P5) and (P8).

\section{Proof of Proposition 2}

(i) For $t=t_{0}$, assume $K_{t_{0}}>0$ and $K_{t_{0}+1}=0$. Then, $k_{i t_{0}+1}=0$ for $i=1,2$. From (P5) of Proposition 1, we get $c_{i t_{0}}=g_{k}\left(r_{t_{0}} k_{i t_{0}}\right)+(1-\delta) k_{i t_{0}}+g_{l}\left(w_{t_{0}} l_{i t_{0}}\right)$. Obviously, $c_{i t_{0}}>0$ for $k_{i t_{0}}>0$. If $k_{i t_{0}}=0, l_{i t_{0}}=0$ implies $c_{i t_{0}}=0$, which is ruled out by (P3) of Proposition 1. Therefore, we always have $c_{i t_{0}}>0$.

We deduce that the left-hand side of the Euler condition (P4) of Proposition 1 has a positive and finite value. Using Assumptions 1 and 3 , we have both $c_{i t_{0}+1}>0$ and $K_{t_{0}+1}>0$, which leads a contradiction. Hence, $K_{t_{0}}>0$ implies $K_{t_{0}+1}>0$. Since $K_{0}>0$, we have $K_{t}>0$ for all $t \geq 0$, by induction.

(ii) For an household $i$, consider an optimal sequence $\left(c_{i t}, k_{i t}, l_{i t}\right)_{t \geq 0}$ such that, without loss of generality, $c_{i t_{1}}=0$ and $c_{i t_{1}+1}>0$ for some $t_{1}$. Let $\varepsilon>0$ and consider the alternative sequence $\left(\widetilde{c}_{i t}, \widetilde{k}_{i t}, \widetilde{l}_{i t}\right)_{t \geq 0}$, such that:

- $\widetilde{l}_{i t}=l_{i t}$ for all $t$;

- $\widetilde{k}_{i t_{1}+1}=k_{i t_{1}+1}-\varepsilon$ and $\widetilde{k}_{i t}=k_{i t}$ for all $t \neq t_{1}+1$;

- $\widetilde{c}_{i t}=c_{i t}$ for all $t \neq t_{1}, t_{1}+1, \widetilde{c}_{i t_{1}}=\varepsilon>0$, and

$$
\widetilde{c}_{i t_{1}+1}=c_{i t_{1}+1}-(1-\delta) \varepsilon+g_{k}\left(r_{t_{1}+1} \widetilde{k}_{i t_{1}+1}\right)-g_{k}\left(r_{t_{1}+1} k_{i t_{1}+1}\right)
$$

Note that $\widetilde{c}_{i t_{1}+1}$ and $\widetilde{k}_{i t_{1}+1}$ are both positive for a sufficiently small $\varepsilon$. Moreover, both the sequences satisfy the sequence of budget constraints (P5).

Comparing the welfare for these two sequences, we show now that $\left(c_{i t}, k_{i t}, l_{i t}\right)_{t \geq 0}$ is no longer optimal:

$$
\begin{aligned}
& \sum_{t=0}^{\infty} \beta_{i}^{t}\left[u_{i}\left(\widetilde{c}_{i t}\right)+v_{i}\left(1-\widetilde{l}_{i t}\right)\right]-\sum_{t=0}^{\infty} \beta_{i}^{t}\left[u_{i}\left(c_{i t}\right)+v_{i}\left(1-l_{i t}\right)\right] \\
= & \beta_{i}^{t_{1}}\left[u_{i}\left(\widetilde{c}_{i t_{1}}\right)-u_{i}\left(c_{i t_{1}}\right)\right]+\beta_{i}^{t_{1}+1}\left[u_{i}\left(\widetilde{c}_{i t_{1}+1}\right)-u_{i}\left(c_{i t_{1}+1}\right)\right] \\
> & \beta_{i}^{t_{1}}\left[u_{i}^{\prime}\left(\widetilde{c}_{i t_{1}}\right)\left(\widetilde{c}_{i t_{1}}-c_{i t_{1}}\right)+\beta_{i} u_{i}^{\prime}\left(\widetilde{c}_{i t_{1}+1}\right)\left(\widetilde{c}_{i t_{1}+1}-c_{i t_{1}+1}\right)\right] \\
= & \beta_{i}^{t_{1}}\left(u_{i}^{\prime}(\varepsilon) \varepsilon+\beta_{i} u_{i}^{\prime}\left(\widetilde{c}_{i t_{1}+1}\right)\left[-(1-\delta) \varepsilon+g_{k}\left(r_{t_{1}+1} \widetilde{k}_{i t_{1}+1}\right)-g_{k}\left(r_{t_{1}+1} k_{i t_{1}+1}\right)\right]\right) \\
\geq & \beta_{i}^{t_{1}}\left(u_{i}^{\prime}(\varepsilon)-\beta_{i} u_{i}^{\prime}\left(\widetilde{c}_{i t_{1}+1}\right)\left[1-\delta+g_{k}^{\prime}\left(r_{t_{1}+1} \widetilde{k}_{i t_{1}+1}\right) r_{t_{1}+1}\right]\right) \varepsilon
\end{aligned}
$$

For $\varepsilon$ sufficiently close to 0 , the last expression is strictly positive and $c_{i t}=0$ cannot be an optimal choice for a household $i$. We deduce that $c_{i t}>0$ for all $t=0, \ldots,+\infty$ and $i=1,2$.

(iii) For $l_{i t}>0$, the following equality holds: $u_{i}^{\prime}\left(c_{i t}\right) g_{l}^{\prime}\left(w_{t} l_{i t}\right) w_{t}=v_{i}^{\prime}\left(1-l_{i t}\right)$. Because $c_{i t}>0$, we get $l_{i t}<1$, by Assumption 1 . 


\section{Proof of Lemma 1}

An autarkic steady state requires $K=0$. However, from Proposition 2, all stationary solutions are characterized by $K>0$, which excludes the existence of an autarkic steady state.

Since $K>0$, we deduce that $k_{i}>0$ for $i=1$ and/or $i=2$. We further have $\beta_{1}\left[1-\delta+g_{k}^{\prime}(0) r\right]>\beta_{2}\left[1-\delta+g_{k}^{\prime}(0) r\right]$ and an agent $i$ will hold capital if $\beta_{i}\left[1-\delta+g_{k}^{\prime}(0) r\right]>1$. Using these two inequalities, we easily conclude that either only households of type 1 or all consumers hold capital.

When $k_{2}=0$, we obviously have $k_{1}>k_{2}$. When $k_{1}$ and $k_{2}$ are both strictly positive, the following equalities are satisfied: $\beta_{1}\left[1-\delta+g_{k}^{\prime}\left(r k_{1}\right) r\right]=$ $\beta_{2}\left[1-\delta+g_{k}^{\prime}\left(r k_{2}\right) r\right]=1$. Because $\beta_{1}>\beta_{2}$ and $g_{k}$ is concave, we also obtain $k_{1}>k_{2}$.

\section{Proof of Proposition 3}

The proof of this proposition consists of three steps.

Step 1. Using Proposition 1, we notice that, for households $i=1$, (T1), (T2) and (T3) are optimal conditions. Moreover, since $c_{1}>0$ and $k_{1}>0$ are constant, and $0<\beta_{1}<1$, the transversality condition (8) holds.

Step 2. For households $i=2$, consider the feasible sequence $\left(\tilde{k}_{2 t+1}, \tilde{l}_{2 t}, \tilde{c}_{2 t}\right)_{t=0}^{\infty}$, with the initial condition $\tilde{k}_{20}=0$. We now compare this path with the stationary solution $\left(k_{2}, l_{2}, c_{2}\right)_{t=0}^{\infty}$, such that $k_{2}=0,1>l_{2}>0$ and $c_{2}=g_{l}\left(w l_{2}\right)$, and show that the stationary solution is optimal. We have:

$$
\begin{aligned}
& \sum_{t=0}^{\infty} \beta_{2}^{t}\left[u_{2}\left(c_{2}\right)+v_{2}\left(1-l_{2}\right)-\left(u_{2}\left(\tilde{c}_{2 t}\right)+v_{2}\left(1-\tilde{l}_{2 t}\right)\right)\right] \\
= & \sum_{t=0}^{\infty} \beta_{2}^{t}\left[u_{2}\left(g_{l}\left(w l_{2}\right)\right)-u_{2}\left(\tilde{c}_{2 t}\right)+v_{2}\left(1-l_{2}\right)-v_{2}\left(1-\tilde{l}_{2 t}\right)\right] \\
\geq & \sum_{t=0}^{\infty} \beta_{2}^{t}\left[u_{2}^{\prime}\left(g_{l}\left(w l_{2}\right)\right)\left(g_{l}\left(w l_{2}\right)-\tilde{c}_{2 t}\right)-v_{2}^{\prime}\left(1-l_{2}\right)\left(l_{2}-\tilde{l}_{2 t}\right)\right] \\
= & \sum_{t=0}^{\infty} \beta_{2}^{t} u_{2}^{\prime}\left(g_{l}\left(w l_{2}\right)\right)\left[g_{l}\left(w l_{2}\right)-g_{l}^{\prime}\left(w l_{2}\right) w\left(l_{2}-\tilde{l}_{2 t}\right)-\tilde{c}_{2 t}\right] \\
= & u_{2}^{\prime}\left(g_{l}\left(w l_{2}\right)\right) \sum_{t=0}^{\infty} \beta_{2}^{t}\left[\widetilde{k}_{2 t+1}-(1-\delta) \widetilde{k}_{2 t}-g_{k}\left(r_{t} \widetilde{k}_{2 t}\right)\right. \\
& \left.+g_{l}\left(w l_{2}\right)-g_{l}\left(w \widetilde{l}_{2 t}\right)-g_{l}^{\prime}\left(w l_{2}\right) w\left(l_{2}-\tilde{l}_{2 t}\right)\right] \\
\geq & u_{2}^{\prime}\left(g_{l}\left(w l_{2}\right)\right) \sum_{t=0}^{\infty} \beta_{2}^{t}\left[\widetilde{k}_{2 t+1}-(1-\delta) \widetilde{k}_{2 t}-g_{k}\left(r_{t} \widetilde{k}_{2 t}\right)\right]
\end{aligned}
$$




$$
\begin{aligned}
= & u_{2}^{\prime}\left(g_{l}\left(w l_{2}\right)\right) \lim _{T \rightarrow+\infty}\left[\beta_{2}^{T} \tilde{k}_{2 T+1}-\left((1-\delta) \widetilde{k}_{20}+g_{k}\left(r \widetilde{k}_{20}\right)\right)\right. \\
& \left.+\sum_{t=1}^{T} \beta_{2}^{t}\left(\widetilde{k}_{2 t} / \beta_{2}-(1-\delta) \widetilde{k}_{2 t}-g_{k}\left(r \widetilde{k}_{2 t}\right)\right)\right] \\
\geq & u_{2}^{\prime}\left(g_{l}\left(w l_{2}\right)\right) \lim _{T \rightarrow+\infty} \sum_{t=1}^{T} \beta_{2}^{t}\left[\gamma_{2}-g_{k}^{\prime}(0) r\right] \widetilde{k}_{2 t} \geq 0
\end{aligned}
$$

Step 3. From the previous steps, note first that $L=n_{1} l_{1}+n_{2} l_{2} \geq n_{2} l_{2}>0$. From $1 \geq \beta_{2}\left[1-\delta+g_{k}^{\prime}(0) r\right]$ and the concavity of $g_{k}$, households of type $i=2$ hold no capital holding at this steady state, i.e., $k_{2}=0$. Therefore, we have $K=n_{1} k_{1}$ and $r=f^{\prime}\left(n_{1} k_{1} / L\right)$, where $k_{1}$ is the solution of $g_{k}^{\prime}\left[f^{\prime}\left(n_{1} k_{1} / L\right) k_{1}\right] f^{\prime}\left(n_{1} k_{1} / L\right)=$ $\gamma_{1}$.

Using Assumptions 2 and 3, there exists a solution to this equation. We further note that neither $g_{k}^{\prime}\left(r k_{1}\right) r>\gamma_{1}$, nor $g_{k}^{\prime}\left(r k_{1}\right) r<\gamma_{1}$ can be a stationary solution. In the first case, it is optimal for patient consumers to accumulate more capital whereas, in the second case, they would decumulate to zero.

\section{Proof of Proposition 4}

The proof of this proposition consists of three steps.

Step 1. Using Proposition 1, we notice that, for all households $(i=1,2),(\mathrm{S} 1)$, (S2) and (S3) are optimal conditions. Moreover, since $c_{i}>0$ and $k_{i}>0$ are constant, and $0<\beta_{i}<1$, the transversality condition (8) holds, for $i=1,2$.

Step 2. To prove that $L>0$, we consider two cases.

- Case 1: $F(K, 0)=0$. After noticing that $L=0$ not only implies $l_{1}=l_{2}=$ 0 , but also $Y=0$, we deduce that $c_{i}=0$, for $i=1,2$, which violates Proposition 2 and leads to a contradiction.

- Case 2: $F(K, 0)>0$. In this case, we have $c_{i}=g_{k}\left(r k_{i}\right)-\delta k_{i}>0$, i.e., $u_{i}^{\prime}\left(c_{i}\right)$ has a finite value and $(\mathrm{S} 2)$ applies. First, notice that equilibria such that $K=0$ are ruled out by Proposition 2. Conversely, if $K>0$, then, $\lim _{L \rightarrow 0^{+}} K / L=+\infty$ and, under Assumption 3, we get $\lim _{L \rightarrow 0^{+}} f^{\prime}(k)<\gamma_{i}$, for $i=1$, 2. Since $0<g_{k}^{\prime}\left(y_{k}\right) \leq 1$ (see Assumption 2), (S2) is no longer satisfied, leading to a contradiction.

This step also proves that there exists $\underline{L}>0$ such that $L>\underline{L}$.

Step 3. According to the second step, we can set $L>0$ in order to prove that there exists a stationary solution $(K, r)$.

First, notice that the steady state value $k_{i}$ is defined by the equality (S2), for $i=1,2$. Assumption 4 implies $\lim _{y_{k} \rightarrow+\infty} g_{k}^{\prime}\left(y_{k}\right)=0$. Since we assume $g_{k}^{\prime}(0) r>\gamma_{2}>\gamma_{1}$, there exist positive values $k_{1}$ and $k_{2}$ satisfying (S2), for $i=1,2$. Furthermore, under Assumption 4, $g_{k}^{\prime}$ is invertible and, according to (S2), $k_{i}$ can be computed as a function of $r$ :

$$
k_{i s}(r) \equiv\left(g_{k}^{\prime}\right)^{-1}\left(\gamma_{i} / r\right) / r
$$


Moreover, since $g_{k}^{\prime}(0) r>\gamma_{2}, r$ belongs to $(\underline{r},+\infty)$, with:

$$
\underline{r} \equiv \gamma_{2} / g_{k}^{\prime}(0)
$$

Since $\lim _{y_{k} \rightarrow+\infty}\left|g_{k}^{\prime}\left(y_{k}\right)-A y_{k}^{-\alpha}\right|=0, \lim _{x_{k} \rightarrow 0^{+}}\left|\left(g_{k}^{\prime}\right)^{-1}\left(x_{k}\right)-\left(A / x_{k}\right)^{1 / \alpha}\right|=$ 0 . Using (64), we obtain: $\lim _{r \rightarrow+\infty} k_{i s}(r)=\lim _{r \rightarrow+\infty}\left(A r^{1-\alpha} / \gamma_{i}\right)^{1 / \alpha}=+\infty$.

Using again (64), we get also: $\lim _{r \rightarrow \underline{\underline{r}}} k_{i s}(r)=\left(g_{k}^{\prime}\right)^{-1}\left(g_{k}^{\prime}(0) \gamma_{i} / \gamma_{2}\right) g_{k}^{\prime}(0) / \gamma_{2}$. More precisely, we have $\lim _{r \rightarrow \underline{r}} k_{2 s}(r)=0$ and $\underline{k}_{1} \equiv \lim _{r \rightarrow \underline{r}} k_{1 s}(r)>0$. Hence, defining $K_{s}(r) \equiv n_{1} k_{1 s}(r)+n_{2} k_{2 s}(r)$ the aggregate supply of capital, we deduce that:

$$
\lim _{r \rightarrow \underline{r}} K_{s}(r)=n_{1} \underline{k}_{1}>0 \text { and } \lim _{r \rightarrow+\infty} K_{s}(r)=+\infty
$$

Note now that the equation $r=f^{\prime}(K / L)$ implicitly defines the aggregate capital demand $K_{d}(r) \equiv L f^{\prime-1}(r)$. Since $f$ is concave, $K_{d}(r)$ is decreasing. Moreover, using Assumption 3, we have:

$$
\lim _{r \rightarrow+\infty} K_{d}(r)=0
$$

Using again Assumption 3, we notice that when $K$ increases from 0 to $+\infty$, $r$ decreases from $+\infty$ to $\lim _{k \rightarrow+\infty} f^{\prime}(k)<\gamma_{1}$, which is strictly smaller than $\underline{r}$. Therefore, there exists $K_{d}(\underline{r})=f^{\prime-1}(\underline{r})$, with $K_{d}(\underline{r})>\bar{K} \equiv \underline{L} f^{\prime-1}(\underline{r})$.

From these last results and (66), there exists a solution $(K, r)$ to the equation $K_{s}(r)=K_{d}(r)$, which determines the existence of a stationary equilibrium, if the condition $n_{1} \underline{k}_{1}<\bar{K}$ is satisfied.

Proof of Lemma 2 We want to prove that the solution $l_{2 t}=l_{2}\left(w_{t}\right)$ of the implicit equation (15) is a well-defined function. Since (15) is a static arbitrage, we omit the time subscripts. Equation (15) is equivalent to:

$$
\varphi_{2}\left(w, l_{2}\right)=w
$$

where $\varphi_{2}\left(w, l_{2}\right) \equiv v_{2}^{\prime}\left(1-l_{2}\right) /\left[u_{2}^{\prime}\left(g_{l}\left(w l_{2}\right)\right) g_{l}^{\prime}\left(w l_{2}\right)\right]$. The partial elasticity of $\varphi_{2}$ w.r.t. $l_{2}$ is

$$
\frac{\partial \varphi_{2}}{\partial l_{2}} \frac{l_{2}}{\varphi_{2}}=\frac{l_{2}}{1-l_{2}} \frac{1}{\sigma_{22}}+\frac{\omega_{12}}{\sigma_{12}}-\omega_{22}>0
$$

because $\sigma_{12}>0, \sigma_{22}>0, \omega_{12} \in(0,1]$ and $\omega_{22} \leq 0$ (Assumptions 1 and $2)$. Then, $\varphi_{2}$ is a continuous and strictly increasing function in $l_{2}$. Given $w$, we have, under Assumption 1 (Inada conditions), $\lim _{l_{2} \rightarrow 0^{+}} \varphi_{2}\left(w, l_{2}\right)=0$ and $\lim _{l_{2} \rightarrow 1^{-}} \varphi_{2}\left(w, l_{2}\right)=+\infty$. Hence, $\varphi_{2}$ crosses $w$ once and only once. In other terms, the solution of equation (68) exists and is unique, ensuring that $l_{2}(w)$ is a well-defined function.

\section{Proof of Corollary 1}

Since we focus on steady states where $k_{1}>0, k_{2}=0, l_{1} \geq 0$ and $l_{2}>0$, we have $k=K / L$ with $K=n_{1} k_{1}$ and $L=n_{1} l_{1}+n_{2} l_{2} \geq n_{2} l_{2}$. 
Using Proposition 3, notice that (T1) and (T3) implicitly define $l_{2}$ as a function of $k, l_{2}(k)$, with:

$$
\frac{d l_{2}}{d k} \frac{k}{l_{2}}=\frac{s}{\sigma} \varepsilon_{2}
$$

where $\varepsilon_{2}$ is given by (16). Using (T1) and (T3) again, we get:

$$
u_{1}^{\prime}\left[g_{k}\left(r(k) k L / n_{1}\right)-\delta k L / n_{1}+g_{l}\left(w(k) l_{1}\right)\right] g_{l}^{\prime}\left(w(k) l_{1}\right) w(k)=v_{1}^{\prime}\left(1-l_{1}\right)
$$

which implicitly defines $l_{1}$ as a function of $k$ and $L, l_{1}(k, L)$. Obviously, the expressions of $\left(k / l_{1}\right) \partial l_{1} / \partial k$ and $\left(L / l_{1}\right) \partial l_{1} / \partial L$ are obtained differentiating (70). Therefore, the equilibrium on labor market $L=n_{1} l_{1}(k, L)+n_{2} l_{2}(k)$ implicitly determines $L=L(k)$, with:

$$
\frac{k L^{\prime}(k)}{L(k)}=\frac{\lambda_{1}\left(k / l_{1}\right) \partial l_{1} / \partial k+\lambda_{2} k l_{2}^{\prime}(k) / l_{2}}{1-\lambda_{1}\left(L / l_{1}\right) \partial l_{1} / \partial L}
$$

By direct inspection of Step 3 in the proof of Proposition 3, we deduce that the number of stationary solutions is determined by the solutions $k$ of:

$$
g_{k}^{\prime}\left(f^{\prime}(k) k L(k) / n_{1}\right) f^{\prime}(k)=\gamma_{1}
$$

Uniqueness requires that the left-hand side of $(72)$ is decreasing in $k$. This is satisfied if the following inequality holds for all $k>0$ :

$$
\rho_{21}\left[1-(1-s) / \sigma+k L^{\prime}(k) / L(k)\right]-(1-s) / \sigma<0
$$

Note that using $g_{k}^{\prime}\left(r k_{1}\right) r=\gamma_{1}$, we obtain $g_{k}\left(r k_{1}\right) / c_{1}=\left(\gamma_{1} / \rho_{11}\right) k_{1} / c_{1}$ and $g_{l}\left(w l_{1}\right) / c_{1}=1-\left(\gamma_{1} / \rho_{11}-\delta\right) k_{1} / c_{1}$. Using these last identities, the expressions of $\left(k / l_{1}\right) \partial l_{1} / \partial k$ and $\left(L / l_{1}\right) \partial l_{1} / \partial L,(69),(71)$ and (73), we are able to deduce the corollary.

\section{Proof of Corollary 2}

We consider stationary solutions such that $k_{1}, k_{2}, l_{2}>0$ and $l_{1}=0$. From the proof of Proposition 4, we notice that a steady state can be defined as a solution of $\psi(r) \equiv K_{d}(r) / K_{s}(r)=1$ for all $r \in(\underline{r},+\infty)$ with $\lim _{r \rightarrow \underline{r}} \psi(r)>$ $\bar{K} /\left(n_{1} \underline{k}_{1}\right)>1$ and $\lim _{r \rightarrow+\infty} \psi(r)=0$. Therefore, there exists a unique steady state if the following condition is satisfied:

$$
r \psi^{\prime}(r) / \psi(r)=r K_{d}^{\prime}(r) / K_{d}(r)-r K_{s}^{\prime}(r) / K_{s}(r)<0
$$

for all $r \in(\underline{r},+\infty)$.

Since $k_{s i}(r)$ is defined by $(64)$ and $K_{s}(r)=\sum_{i=1}^{2} n_{i} k_{s i}(r)$, we get $r k_{s i}^{\prime}(r) / k_{s i}(r)$ $=-1-1 / \rho_{2 i}$ and:

$$
r K_{s}^{\prime}(r) / K_{s}(r)=-\sum_{i=1}^{2} \kappa_{i}\left(1+\rho_{2 i}\right) / \rho_{2 i}
$$


Using $w=w(k)$ and $r=r(k)$, the real wage can be redefined as a function of the real interest rate $w \equiv w(r)$, with $r w^{\prime}(r) / w(r)=-s /(1-s)$. Hence, using (S1) and (S3), $l_{i} \equiv l_{i}(r)$ is implicitly defined by:

$$
u_{i}^{\prime}\left[g_{k}\left(r k_{i}(r)\right)-\delta k_{i}(r)+g_{l}\left(w(r) l_{i}\right)\right] g_{l}^{\prime}\left(w(r) l_{i}\right) w(r)=v_{i}^{\prime}\left(1-l_{i}\right)
$$

The elasticity $r l_{i}^{\prime}(r) / l_{i}(r)$ is obtained by differentiating (76): $r l_{i}^{\prime}(r) / l_{i}(r)=$ $-\tilde{\varepsilon}_{i} s /(1-s)$, where $\tilde{\varepsilon}_{i}$ is given by (17). Moreover, the equality $L=\sum_{i=1}^{2} n_{i} l_{i}(r)$ $\equiv L(r)$ ensures the equilibrium on the labor market, with $r L^{\prime}(r) / L(r)=$ $\sum_{i=1}^{2} \lambda_{i} r l_{i}^{\prime}(r) / l_{i}(r)$.

Using the proof of Proposition 4 and the equilibrium on the labor market, we get $K_{d}(r)=L(r) f^{\prime-1}(r)$, with:

$$
r K_{d}^{\prime}(r) / K_{d}(r)=\sum_{i=1}^{2} \lambda_{i} r l_{i}^{\prime}(r) / l_{i}(r)-\sigma /(1-s)
$$

Substituting (75), (77) and the expressions of $r l_{i}^{\prime}(r) / l_{i}(r)$ into (74), we deduce the corollary.

\section{Proof of Proposition 5}

Differentiating (20) and using (21) gives

$$
\frac{\partial k}{\partial n_{1}} \frac{n_{1}}{k}=\frac{\rho_{21}}{\varepsilon_{H k}}=-\frac{\partial k}{\partial n_{2}} \frac{n_{2}}{k}
$$

From $K=k n_{2} l_{2}(k)$ and (21), we get

$$
\frac{\partial K / \partial k}{K / k}=1+\frac{s}{\sigma} \varepsilon_{2}=\frac{\varepsilon_{H k}}{\rho_{21}}+\frac{1+\rho_{21}}{\rho_{21}} \frac{1-s}{\sigma}
$$

Therefore,

$$
\begin{aligned}
\frac{d K}{d n_{1}} \frac{n_{1}}{K}=\frac{\partial K / \partial k}{K / k} \frac{\partial k / \partial n_{1}}{k / n_{1}}=\left(1+\frac{s}{\sigma} \varepsilon_{2}\right) \frac{\rho_{21}}{\varepsilon_{H k}} \\
\frac{d K}{d n_{2}} \frac{n_{2}}{K}=\frac{\partial K / \partial k}{K / k} \frac{\partial k / \partial n_{2}}{k / n_{2}}+1=-\frac{1-s}{\sigma} \frac{1+\rho_{21}}{\varepsilon_{H k}}
\end{aligned}
$$

Cases (i) and (ii) immediately follow.

\section{Proof of Proposition 6}

From $Y=f(k) n_{2} l_{2}(k)$ and (21), we get

$$
\frac{\partial Y / \partial k}{Y / k}=s\left(1+\frac{\varepsilon_{2}}{\sigma}\right)=\frac{\varepsilon_{H k}}{\rho_{21}}-\frac{1-s}{\rho_{21}}\left(\rho_{21}-\frac{1+\rho_{21}}{\sigma}\right)
$$


Using (78) and (79), we obtain

$$
\begin{aligned}
\frac{d Y}{d n_{1}} \frac{n_{1}}{Y} & =\frac{\partial Y / \partial k}{Y / k} \frac{\partial k / \partial n_{1}}{k / n_{1}}=s\left(1+\frac{\varepsilon_{2}}{\sigma}\right) \frac{\rho_{21}}{\varepsilon_{H k}} \\
\frac{d Y}{d n_{2}} \frac{n_{2}}{Y} & =\frac{\partial Y / \partial k}{Y / k} \frac{\partial k / \partial n_{2}}{k / n_{2}}+1=\frac{1-s}{\varepsilon_{H k}}\left(\rho_{21}-\frac{1+\rho_{21}}{\sigma}\right)
\end{aligned}
$$

Cases (i) and (ii) easily follow.

\section{Proof of Proposition 7}

We have:

$$
\frac{\partial I_{1} / \partial k}{I_{1} / k}=\rho_{11}\left(1-\frac{1-s-s \varepsilon_{2}}{\sigma}\right), \frac{\partial I_{1} / \partial \nu}{I_{1} / \nu}=-\rho_{11}, \frac{\partial I_{2} / \partial k}{I_{2} / k}=\frac{s}{\sigma}\left(1+\varepsilon_{2}\right) \omega_{12}
$$

and, from (20) and (21), $(\nu / k) \partial k / \partial \nu=\rho_{21} / \varepsilon_{H k}$. Using these preliminary results, (22) and (23) imply:

$$
\begin{aligned}
& \frac{d I_{1}}{d \nu} \frac{\nu}{I_{1}}=\frac{\partial I_{1} / \partial k}{I_{1} / k} \frac{\partial k / \partial \nu}{k / \nu}+\frac{\partial I_{1} / \partial \nu}{I_{1} / \nu}=\frac{\rho_{11}}{\varepsilon_{H k}} \frac{1-s}{\sigma} \\
& \frac{d I_{2}}{d \nu} \frac{\nu}{I_{2}}=\frac{\partial I_{2} / \partial k}{I_{2} / k} \frac{\partial k / \partial \nu}{k / \nu}=\frac{\rho_{21}}{\varepsilon_{H k}} \frac{s}{\sigma}\left(1+\varepsilon_{2}\right) \omega_{12}
\end{aligned}
$$

with $1+\varepsilon_{2}>0$.

\section{Proof of Proposition 8}

Differentiating $W_{2}=\left[u_{2}\left(I_{2}\right)+v_{2}\left(1-l_{2}\right)\right] /\left(1-\beta_{2}\right)$, we get:

$$
d W_{2}=\frac{c_{2} u_{2}^{\prime}\left(c_{2}\right)}{1-\beta_{2}}\left[\frac{d I_{2}}{I_{2}}-\omega_{12} \frac{d l_{2}}{l_{2}}\right]
$$

which implies:

$$
\begin{aligned}
d W_{2} & =\frac{c_{2} u_{2}^{\prime}\left(c_{2}\right)}{1-\beta_{2}}\left[\left(1+\varepsilon_{2}\right) \omega_{12} \frac{s}{\sigma} \frac{\rho_{21}}{\varepsilon_{H k}} \frac{d \nu}{\nu}-\varepsilon_{2} \omega_{12} \frac{s}{\sigma} \frac{\rho_{21}}{\varepsilon_{H k}} \frac{d \nu}{\nu}\right] \\
& =\frac{c_{2} u_{2}^{\prime}\left(c_{2}\right)}{1-\beta_{2}} \omega_{12} \frac{s}{\sigma} \frac{\rho_{21}}{\varepsilon_{H k}} \frac{d \nu}{\nu}
\end{aligned}
$$

Proposition 8 immediately follows.

Definition of $l_{2} \equiv l_{2}\left(k, T_{l}, t_{l}\right)$

From (T1), (T3) of Proposition 3 and (25), $l_{2} \equiv l_{2}\left(k, T_{l}, t_{l}\right)$ is implicitly defined by the arbitrage $u_{2}^{\prime}\left[\left(1-t_{l}\right) w(k) l_{2}-T_{l}\right]\left(1-t_{l}\right) w(k)=v_{2}^{\prime}\left(1-l_{2}\right)$. Totally differentiating this equation, we obtain the following three elasticities:

$$
\frac{\partial l_{2}}{\partial k} \frac{k}{l_{2}}=\varepsilon_{2} \frac{s}{\sigma}, \frac{\partial l_{2}}{\partial T_{l}} \frac{T_{l}}{l_{2}}=-\varepsilon_{2} \frac{1-q_{2}}{1-q_{2} \sigma_{12}}>0, \frac{\partial l_{2}}{\partial t_{l}} \frac{t_{l}}{l_{2}}=-\varepsilon_{2} \frac{t_{l}}{1-t_{l}}
$$


where $\varepsilon_{2}$ is now given by (26).

\section{Proof of Proposition 9}

Differentiating $K=k\left(t_{k}\right) n_{2} l_{2}\left(k\left(t_{k}\right), T_{l}, t_{l}\right)$ with respect to $\left(T_{k}, T_{l}, t_{k}, t_{l}\right)$ and using (28) and (83), we get:

$$
\left[\begin{array}{ll}
\frac{\partial K}{\partial T_{k}} \frac{T_{k}}{K} & \frac{\partial K}{\partial T_{T}} \frac{T_{l}}{K} \\
\frac{\partial K}{\partial t_{k}} \frac{t_{k}}{K} & \frac{\partial K}{\partial t_{l}} \frac{t_{l}}{K}
\end{array}\right]=\left[\begin{array}{cc}
0 & -\frac{1-q_{2}}{1-q_{2} \sigma_{12}} \varepsilon_{2}>0 \\
-\frac{t_{k}}{1-t_{k}} \frac{\sigma+s \varepsilon_{2}}{1-s} & -\frac{t_{l}}{1-t_{l}} \varepsilon_{2}
\end{array}\right]
$$

The proposition easily follows.

\section{Proof of Proposition 10}

Differentiating $Y=f\left(k\left(t_{k}\right)\right) n_{2} l_{2}\left(k\left(t_{k}\right), T_{l}, t_{l}\right)$ with respect to $\left(T_{k}, T_{l}, t_{k}, t_{l}\right)$ and using (28) and (83), we get:

$$
\left[\begin{array}{cc}
\frac{\partial Y}{\partial T_{k}} \frac{T_{k}}{Y} & \frac{\partial Y}{\partial T_{l}} \frac{T_{l}}{Y} \\
\frac{\partial Y}{\partial t_{k}} \frac{t_{k}}{Y} & \frac{\partial Y}{\partial t_{l}} \frac{t_{l}}{Y}
\end{array}\right]=\left[\begin{array}{cc}
0 & -\frac{1-q_{2}}{1-q_{2} \sigma_{12}} \varepsilon_{2}>0 \\
-\frac{s}{1-s} \frac{t_{k}}{1-t_{k}}\left(\sigma+\varepsilon_{2}\right) & -\frac{t_{l}}{1-t_{l}} \varepsilon_{2}
\end{array}\right]
$$

The proposition immediately follows.

\section{Proof of Proposition 11}

Differentiating $I_{1}=\left(1-t_{k}\right) r\left(k\left(t_{k}\right)\right) k\left(t_{k}\right) l_{2}\left(k\left(t_{k}\right), T_{l}, t_{l}\right) n_{2} / n_{1}-T_{k}$ with respect to $\left(T_{k}, T_{l}, t_{k}, t_{l}\right)$, we get:

$$
\left[\begin{array}{ll}
\frac{\partial I_{1}}{\partial T_{k}} \frac{T_{k}}{I_{1}} & \frac{\partial I_{1}}{\partial T_{1}} \frac{T_{l}}{I_{1}} \\
\frac{\partial I_{1}}{\partial t_{k}} \frac{t_{k}}{I_{1}} & \frac{\partial I_{1}}{\partial t_{l}} \frac{t_{l}}{I_{1}}
\end{array}\right]=\left[\begin{array}{cc}
-\frac{1-q_{1}}{q_{1}}<0 & -\frac{1-q_{2}}{1-q_{2} q_{1}} \frac{\varepsilon_{2}}{q_{1}}>0 \\
-\frac{t_{k}}{1-t_{k}} \frac{\sigma+s \varepsilon_{2}}{(1-s) q_{1}} & -\frac{t_{l}}{1-t_{l}} \frac{\varepsilon_{2}}{q_{1}}
\end{array}\right]
$$

The proposition easily follows.

\section{Proof of Proposition 12}

Differentiating $I_{2}=\left(1-t_{l}\right) w\left(k\left(t_{k}\right)\right) l_{2}\left(k\left(t_{k}\right), T_{l}, t_{l}\right)-T_{l}$ with respect to $T_{k}, T_{l}, t_{k}$ and $t_{l}$, we get:

$$
\left[\begin{array}{cc}
\frac{\partial I_{2}}{\partial T_{k}} \frac{T_{k}}{I_{2}} & \frac{\partial I_{2}}{\partial T_{2}} \frac{T_{l}}{I_{2}} \\
\frac{\partial I_{2}}{\partial t_{k}} \frac{t_{k}}{I_{2}} & \frac{\partial I_{2}}{\partial t_{l}} \frac{t_{l}}{I_{2}}
\end{array}\right]=\left[\begin{array}{cc}
0 & -\frac{1-q_{2}}{q_{2}}\left(1+\frac{\varepsilon_{2}}{1-q_{2} \sigma_{12}}\right)<0 \\
-\frac{t_{k}}{1-t_{k}} \frac{1+\varepsilon_{2}}{q_{2}} \frac{s}{1-s}<0 & -\frac{t_{l}}{1-t_{l}} \frac{1+\varepsilon_{2}}{q_{2}}<0
\end{array}\right]
$$

The proposition easily follows.

\section{Proof of Proposition 13}

Because $c_{2}=I_{2}$, the welfare of an impatient agent becomes $W_{2}=\left[u_{2}\left(I_{2}\right)\right.$ $\left.+v_{2}\left(1-l_{2}\right)\right] /\left(1-\beta_{2}\right)$. Differentiating this equation, we get:

$$
d W_{2}=\frac{c_{2} u_{2}^{\prime}\left(c_{2}\right)}{1-\beta_{2}}\left(\frac{d I_{2}}{I_{2}}-\frac{1}{q_{2}} \frac{d l_{2}}{l_{2}}\right)
$$


Using the elasticities of $l_{2}\left(k, T_{l}, t_{l}\right)$ and the proof of Proposition 12, we obtain the following derivatives:

$$
\left[\begin{array}{cc}
T_{k} \frac{\partial W_{2}}{\partial T_{k}} & T_{l} \frac{\partial W_{2}}{\partial T_{l}} \\
t_{k} \frac{\partial W_{2}}{\partial t_{k}} & t_{l} \frac{\partial W_{2}}{\partial t_{l}}
\end{array}\right]=-\frac{c_{2}}{q_{2}} \frac{u_{2}^{\prime}\left(c_{2}\right)}{1-\beta_{2}}\left[\begin{array}{cc}
0 & 1-q_{2}>0 \\
\frac{s}{1-s} \frac{t_{k}}{1-t_{k}}>0 & \frac{t_{l}}{1-t_{l}}>0
\end{array}\right]
$$

The proposition immediately follows.

\section{Proof of Lemma 3}

Since (29) is a static arbitrage, we omit the time subscripts. To prove that the solution $l_{1}\left(w, c_{1}\right)$ of the consumption-labor arbitrage (29) is a well-defined function, we note that equation (29) is equivalent to:

$$
\varphi_{1}\left(w, l_{1}, c_{1}\right)=w
$$

where $\varphi_{1}\left(w, l_{1}, c_{1}\right) \equiv v_{1}^{\prime}\left(1-l_{1}\right) /\left[u_{1}^{\prime}\left(c_{1}\right) g_{l}^{\prime}\left(w l_{1}\right)\right]$. The elasticity of $\varphi_{1}$ w.r.t. $l_{1}$ is:

$$
\frac{\partial \varphi_{1}}{\partial l_{1}} \frac{l_{1}}{\varphi_{1}}=\frac{l_{1}}{1-l_{1}} \frac{1}{\sigma_{21}}-\omega_{21}>0
$$

because $\sigma_{21}>0$ and $\omega_{21} \leq 0$ (Assumptions 1 and 2). Then, $\varphi_{1}$ is a continuous and strictly increasing function of $l_{1}$. Given $w$ and $c_{1}$, we further have $\lim _{l_{1} \rightarrow 0^{+}} v_{1}^{\prime}\left(1-l_{1}\right)<u_{1}^{\prime}\left(c_{1}\right) g_{l}^{\prime}\left(w l_{1}\right) w$ or, equivalently, $\lim _{l_{1} \rightarrow 0^{+}} \varphi_{1}\left(w, l_{1}, c_{1}\right)<$ $w$ and, under Assumption 1 (Inada conditions), $\lim _{l_{1} \rightarrow 1^{-}} \varphi_{1}\left(w, l_{1}, c_{1}\right)=+\infty$. Such boundary conditions, jointly with continuity and monotonicity (see (85)), ensure that $\varphi_{1}$ crosses $w$ once as $l_{1}$ increases, that is the solution $l_{1}$ of equation (84) is unique.

\section{Proof of Proposition 14}

First, notice that $\lambda_{1} \varepsilon_{1} /\left(1+\omega_{21}\right)>0$ and $\rho_{11} \in(0,1]$ entail $Z>0$. Since $D(+\infty)=1 / \beta>1$ and $T(+\infty)=1+1 / \beta-\gamma \rho_{21} Z>1+D(+\infty)$, the endpoint $(T(+\infty), D(+\infty))$ lies in the open cone $\Xi \equiv\{(T, D):|1+D|<T\}$ included in the saddle-point region. Linearity of $\Sigma$ and monotonicity along $\Sigma$ imply that there is a critical value $\sigma^{*}$ such that $\sigma>\sigma^{*}$ entails $(T(\sigma), D(\sigma)) \in \Xi$.

\section{Proof of Lemma 4}

To prove (i), we compute the following derivatives:

$$
\frac{\partial \sigma_{P}}{\partial \omega_{22}}=\frac{\partial \sigma_{F}}{\partial \omega_{22}}=-s \frac{1+\frac{1}{\sigma_{22}} \frac{l_{2}}{1-l_{2}}}{\left(\frac{\omega_{12}}{\sigma_{12}}-\omega_{22}+\frac{1}{\sigma_{22}} \frac{l_{2}}{1-l_{2}}\right)^{2}}<0
$$

while (ii) is obtained from:

$$
\begin{aligned}
& \frac{\partial \sigma_{P}}{\partial \rho_{21}}=-\frac{1-s}{\rho_{21}^{2}}<0 \\
& \frac{\partial \sigma_{F}}{\partial \rho_{21}}=-(1-s) \frac{\gamma Z[2(2-\delta)+\gamma Z]}{\left[2(1+\beta) / \beta-\rho_{21} \gamma Z\right]^{2}}<0
\end{aligned}
$$


Solving $\partial\left(\sigma_{P}-\sigma_{F}\right) / \partial\left|\rho_{21}\right|=\partial \sigma_{F} / \partial \rho_{21}-\partial \sigma_{P} / \partial \rho_{21}>0$, we get (iii).

\section{Proof of Lemma 5}

We compute the following expression

$$
\frac{\partial S}{\partial \omega_{21}}=\lambda_{1} \frac{\beta\left[\gamma h \frac{1-s}{s}+\sigma_{11} \frac{h-h^{*}}{h^{*}}\left(\frac{\gamma}{\rho_{11}}-\delta+\lambda_{1} h \frac{1-s}{s} \frac{\gamma}{\omega_{11}}\right)\right]+1-\beta}{\left(\left(\frac{1}{\sigma_{21}} \frac{l_{1}}{1-l_{1}}-\omega_{21}\right)\left[1-h \lambda_{1}\left(1+\varepsilon_{1}\right)+\beta \frac{\lambda_{1} \varepsilon_{1}}{1+\omega_{21}}-Z\right]\right)^{2}}
$$

Since $h^{*}<1<\underline{h}<h$, we obtain $\partial S / \partial \omega_{21}>0$.

\section{Proof of Lemma 6}

To prove cases (i) and (ii), we compute the following derivatives:

$$
\begin{aligned}
\frac{\partial \sigma_{H}}{\partial \omega_{22}} & =\frac{\partial \sigma_{F}}{\partial \omega_{22}}=-s \lambda_{2} \frac{1+\frac{1}{\sigma_{22}} \frac{l_{2}}{1-l_{2}}}{\left(\frac{\omega_{12}}{\sigma_{12}}-\omega_{22}+\frac{1}{\sigma_{22}} \frac{l_{2}}{1-l_{2}}\right)^{2}}<0 \\
\frac{\partial \sigma_{F}}{\partial \omega_{21}} & =-s \lambda_{1} \frac{\left(1+h \frac{1-s}{s} \frac{\beta \gamma}{1+\beta}\right)\left(\frac{1}{h^{*}}+\frac{1-s}{s} \frac{\beta \gamma}{2}\right)}{\left(\frac{l_{1}}{1-l_{1}} \frac{1}{\sigma_{21}}-\omega_{21}\right)^{2}}<0
\end{aligned}
$$

To establish case (iii), we observe that $h>\underline{h}$ implies:

$$
\frac{\partial \sigma_{H}}{\partial \omega_{21}}=-\frac{\lambda_{1}}{h^{*}} \frac{s+(1-s)\left(h-\beta h^{*}\right) \frac{\beta \gamma}{1-\beta}}{\left(\frac{1}{\sigma_{21}} \frac{l_{1}}{1-l_{1}}-\omega_{21}\right)^{2}}<0
$$

For case (iv), we note that $\omega_{21}^{*}<0$ implies:

$$
h\left[4-(1-\beta) h^{*} \gamma \frac{1-s}{s}\right]-h^{*} \frac{(1+\beta)^{2}}{\beta}>0
$$

that is,

$\frac{\partial\left(\sigma_{F}-\sigma_{H}\right)}{\partial \omega_{21}}=\frac{1}{2} \frac{1-s}{s} \frac{\beta \gamma}{1-\beta^{2}} \frac{\lambda_{1}}{h^{*}} \frac{4 s \beta h-h^{*}\left[s(1+\beta)^{2}+(1-s)(1-\beta) h \beta \gamma\right]}{\left(\frac{1}{\sigma_{21}} \frac{l_{1}}{1-l_{1}}-\omega_{21}\right)^{2}}>0$

\section{References}

[1] Attanasio, O. (1999), Consumption, in Handbook of Macroeconomics, Taylor, J., Woodford, M. (Eds.). North-Holland, Amsterdam. 
[2] Bacchetta, P. and S. Gerlach (1997), Consumption and Credit Constraints: International Evidence, Journal of Monetary Economics 40, 207-238.

[3] Becker, R. A. (1980), On the Long-Run Steady State in a Simple Dynamic Model of Equilibrium with Heterogeneous Households, Quarterly Journal of Economics 95, 375-382.

[4] Becker, R. A. and C. Foias (1987), A Characterization of Ramsey Equilibrium, Journal of Economic Theory 41, 173-184.

[5] Becker, R. A. and C. Foias (1994), The Local Bifurcation of Ramsey Equilibrium, Economic Theory 4, 719-744.

[6] Becker, R. A. and C. Foias (2007), Strategic Ramsey Equilibrium Dynamics, Journal of Mathematical Economics 43, 318-346.

[7] Benhabib, J. and R. Farmer (1994), Indeterminacy and Increasing Returns, Journal of Economic Theory 63, 19-41.

[8] Bosi, S. and T. Seegmuller (2007), On the Ramsey Equilibrium with Heterogeneous Consumers and Endogenous Labor Supply, CES Working Paper 2007.03, University Paris 1.

[9] Cushing, M. (1992), Liquidity Constraints and Aggregate Consumption Behavior, Economic Inquiry 30, 134-153.

[10] Dromel, N. and P. Pintus (2007), Are Progressive Income Taxes Stabilizing?, Journal of Public Economic Theory, in press.

[11] Grandmont, J.-M., P. Pintus and R. de Vilder (1998), Capital-labour Substitution and Competitive Nonlinear Endogenous Business Cycles, Journal of Economic Theory 80, 14-59.

[12] Guo, J.T. and K. Lansing (1998), Indeterminacy and Stabilization Policy, Journal of Economic Theory 82, 481-490.

[13] Lloyd-Braga, T., L. Modesto and T. Seegmuller (2008), Tax Rate Variability and Public Spending as Sources of Indeterminacy, Journal of Public Economic Theory 10, 399-421.

[14] Mankiw, N.G. (2000), The Savers-Spenders Theory of Fiscal Policy, American Economic Review 90, 120-125.

[15] Michel, P. and P. Pestieau (1999), Fiscal Policy when Individuals Differ with Regard to Altruism and Labor Supply, Journal of Public Economic Theory 1, 187-203.

[16] Musgrave, R.A. and T. Thin (1948), Income Tax Progression, 1929-1948, Journal of Political Economy 56, 498-514. 
[17] Sarte, P.-D. (1997), Progressive Taxation and Income Inequality in Dynamic Competitive Equilibrium, Journal of Public Economics 66, 145-171.

[18] Schmitt-Grohé, S. and M. Uribe (1997), Balanced-Budget Rules, Distortionary Taxes, and Aggregate Instability, Journal of Political Economy 105, 976-1000.

[19] Sorger, G. (2002), On the Long-Run Distribution of Capital in the Ramsey Model, Journal of Economic Theory 105, 226-243.

[20] Sorger, G. (2004), Differentiated Capital and the Distribution of Wealth, mimeo, University of Vienna.

[21] Sorger, G. (2008), Strategic Saving Decisions in the Infinite-Horizon Model, Economic Theory, in press.

[22] Thibault, E. (2005), Existence and Characteristics of Rentiers: A SaversSpenders Theory Approach, Economic Theory 25, 401-419.

[23] Woodford, M. (1986), Stationary Sunspot Equilibria in a Finance Constrained Economy, Journal of Economic Theory 40, 128-137.

[24] Woodford, M. (1989), Imperfect Financial Intermediation and Complex Dynamics, in Economic Complexity: Chaos, Sunspots, Bubbles and Nonlinearity, Barnett, W. et al., eds. 